\title{
Spo11 and the Formation of DNA Double-Strand Breaks in Meiosis
}

\author{
Scott Keeney \\ Molecular Biology Program, Memorial Sloan-Kettering Cancer Center, 1275 York Ave., New York, \\ NY 10021 USA, s-keeney@ski.mskcc.org
}

\begin{abstract}
Meiotic recombination is carried out through a specialized pathway for the formation and repair of DNA double-strand breaks made by the Spo11 protein, a relative of archaeal topoisomerase VI. This review summarizes recent studies that provide insight to the mechanism of DNA cleavage by Spo11, functional interactions of Spo11 with other proteins required for break formation, mechanisms that control the timing of recombination initiation, and evolutionary conservation and divergence of these processes.
\end{abstract}

\section{Double-Strand Breaks and the Initiation of Meiotic Recombination}

Most sexually reproducing organisms use recombination to connect homologous paternal and maternal chromosomes to one another during prophase I of meiosis (Page and Hawley 2003; Petronczki et al. 2003). This connection is essential for accurate chromosome segregation at the first meiotic division1.

Meiotic recombination has at its heart the formation and subsequent repair of DNA doublestrand breaks (DSBs) (reviewed in Keeney 2001). The major steps along the recombination pathway have been best defined in the budding yeast Saccharomyces cerevisiae (Figure 1) (Bishop and Zickler 2004; Hunter 2007). DSB formation is catalyzed by Spo11, which appears to act via a topoisomerase-like reaction to generate a transient, covalent proteinDNA intermediate (de Massy et al. 1995; Keeney and Kleckner 1995; Liu et al. 1995; Bergerat et al. 1997; Keeney et al. 1997). After DSBs are formed, Spo11 is removed from the DNA (Neale et al. 2005) and the $5^{\prime}$ strand termini are nucleolytically resected to yield variable-length, 3' single-stranded tails (Sun et al. 1991; Bishop et al. 1992). In a series of reactions dependent on yeast homologs of bacterial RecA (Bishop et al. 1992; Shinohara et al. 1992), these tails undergo strand invasion of intact homologous duplexes, ultimately giving rise to mature recombinant products (Smith and Nicolas 1998; Paques and Haber 1999; Bishop and Zickler 2004). The repair of any given meiotic DSB can result in either reciprocal exchange of the chromosome arms flanking the break (a crossover), or no exchange of flanking arms (a noncrossover or parental configuration).

Ample evidence indicates that DSBs are initiators of meiotic recombination in other organisms as well. Meiosis-specific DSBs have been demonstrated in Schizosaccharomyces pombe, dependent on genes known to be required for meiotic recombination, including the SPO11 homolog rec12 ${ }^{+}$(Cervantes et al. 2000). Meiotic DNA strand breaks have also been detected by PCR or in situ DNA labeling assays in mouse spermatocytes (Zenvirth et al.

\footnotetext{
${ }^{1}$ Notable exceptions to this pattern are dipteran males (e.g., Drosophila melanogaster) and lepidopteran females (e.g., the silk moth Bombyx mori), in which meiotic segregation of homologous chromosomes is achieved without recombination (Rasmussen 1977; McKee 1998; McKim et al. 1998). In both classes of insect, however, the other sex does utilize meiotic recombination.
} 
2003; Qin et al. 2004). Although DSBs have not been directly detected by physical assays in other organisms, Spo11 orthologs are present and are required for initiation of meiotic recombination (detected genetically or cytologically) in all sexually reproducing species tested (discussed further in Section 2). In many organisms, the recombination defect in spoll mutants can be at least partially rescued by production of DSBs from an exogenous source such as ionizing radiation (Thorne and Byers 1993; Dernburg et al. 1998; Celerin et al. 2000; Liu et al. 2002; Storlazzi et al. 2003). Finally, $\gamma \mathrm{H} 2 \mathrm{AX}$ (a phosphorylated form of histone H2AX that is thought to be a marker for the location of DSBs) appears on meiotic chromosomes in many organisms from leptonema through zygonema in a Spol1-dependent fashion (reviewed in Fernandez-Capetillo et al. 2004). Thus, DSB formation appears to be a universal feature of meiotic recombination.

There are a number of important questions concerning the initiation of meiotic recombination. For example, what are the biochemical mechanisms of DSB formation and the early steps in processing DSB ends to prepare them for subsequent strand exchange reactions? What are the functions of the many proteins that collaborate with Spo11 to promote DSB formation? How is Spo11 activity controlled so that it functions only at the right time and place? How are specific sites chosen for DSB formation?

This review will focus on relatively recent findings that address these questions. Much of our understanding of these processes derives from studies of Saccharomyces cerevisiae, but increasing detail is emerging from studies of other organisms as well. Similarities and differences between organisms are informative with respect to evolutionary conservation of the mechanism and regulation of meiotic recombination initiation.

\section{Spo11 and Its Relation to Archaeal Topoisomerase VI}

\subsection{Topoisomerase VI}

Because Spo11 is related to DNA topoisomerases, a consideration of how topoisomerases work is useful for understanding the mechanism of Spo11 action during meiosis. Topoisomerases catalyze DNA strand breakage and reunion reactions in order to solve topological problems inherent to chromosome metabolism. Various topoisomerases can relax supercoiled DNA, supercoil relaxed DNA, and/or link and unlink intertwined single stranded or duplex DNA molecules (reviewed in Champoux 2001; Wang 2002; Corbett and Berger 2004). These topological changes are carried out through a series of transesterification reactions in which a tyrosine residue on the enzyme attacks a phosphorus in the DNA, forming a tyrosyl phosphodiester link to the DNA and simultaneously severing the DNA backbone (Figure 2). The resulting DNA break provides a gate through which another DNA strand or duplex can pass. The DNA backbone is subsequently resealed through the reverse of the cleavage reaction. Topoisomerases are broadly grouped into two main categories: type I enzymes cleave a single strand, whereas type II enzymes cleave both strands of a duplex in concert. Topoisomerases can also be distinguished based on the polarity of their covalent attachment to DNA: some enzymes generate a $3^{\prime}$ attachment, while others (including all type II enzymes) become linked to $5^{\prime}$ strand termini (Figure 2).

Most type II topoisomerases of mammals, yeast, and other eukaryotes belong to a single group (the type IIA family), which also includes gyrase and topoisomerase IV of bacteria (Gadelle et al. 2003; Corbett and Berger 2004). Members of this family are also found in some phages and viruses and in some archaeal species. Type IIA topoisomerases share substantial protein sequence and structural homology with one another. They are modular enzymes with subdomains that carry out distinct functions: binding and cleaving DNA, binding and hydrolyzing ATP, and transducing ATP-dependent conformational signals between domains (Corbett and Berger 2004). The catalytic tyrosine residue is carried in an 
alpha-helical domain similar to the DNA binding domain of catabolite activating protein (CAP) (Berger et al. 1998); additional active site residues are provided in trans from the dimer partner in the form of a divalent metal ion binding pocket formed by a module called a Toprim domain (Aravind et al. 1998; Berger et al. 1998). ATP binding and hydrolysis are carried out by a domain related to ATPase domains of heat shock protein 90 , the CheA histidine kinase, and the MutL component of DNA mismatch repair systems (Dutta and Inouye 2000).

The major archaeal type II topoisomerase (called topoisomerase VI) is structurally very different, and is thus in a separate family, called type IIB (Bergerat et al. 1997; Nichols et al. 1999). TopoVI has the same structural and catalytic modules as type IIA enzymes, but the sequence conservation between TopoVI and type IIA enzymes within the modules is limited (as low as $\sim 10 \%$ identity) and the order of the modules in the polypeptide sequence and their three-dimensional arrangement differs (Gadelle et al. 2003; Corbett and Berger 2004). TopoVI is an $\mathrm{A}_{2} \mathrm{~B}_{2}$ heterotetramer. The A subunit carries the DNA cleaving catalytic tyrosine and the Toprim metal-binding domain. The B subunit carries the ATP binding domain and a domain thought to be involved in transducing conformational signals between the subunits. Direct enzymatic analysis showed that TopoVI cleaves DNA to yield a twonucleotide 5 ' overhang and that cleavage by the A subunit is absolutely dependent on both the B subunit and ATP (Buhler et al. 1998; Buhler et al. 2001).

Structures are available for fragments of TopoVI A and B subunits (Nichols et al. 1999; Corbett and Berger 2003; Corbett and Berger 2005). Based on these, Berger and colleagues have proposed a rough structural model for the holoenzyme as follows: Two B subunits sit atop a dimer of A subunits that themselves bind to the DNA that will be broken (the gate, or "G" duplex) (Corbett and Berger 2003; Corbett and Berger 2004) (Figure 3a). The B subunits are thought to contact the CAP domains of the A subunits and thus to influence directly the position of the catalytic tyrosine relative to DNA and to the metal binding pocket in the Toprim domain. Upon ATP binding, the B subunits dimerize (Corbett and Berger 2003) (Figure 3b), trapping a second DNA duplex (the transfer, or "T" duplex) and activating cleavage of the G duplex. ATP hydrolysis then drives a conformational change that disrupts the A subunit dimer interface, breaking the G duplex and opening a gate through which the T duplex is expelled (Figure 3c). Release of ADP allows the enzyme to recycle to the starting state. In its broad outlines, this ATP-driven gating model for strand passage for TopoVI is analogous to that proposed for the type IIA enzymes (Roca et al. 1996).

\subsection{Spo11}

The discovery that meiotic DSBs are made by a topoisomerase relative grew from studies in S. cerevisiae a little over a decade ago. Early observations established that meiotic DSBs have protein covalently attached to the 5' DNA strand termini on both sides of the break in mutants (rad50S, mrel 1S, and sae2A) that accumulate unrepaired DSBs that are not exonucleolytically resected (de Massy et al. 1995; Keeney and Kleckner 1995; Liu et al. 1995). This finding suggested that DSBs are generated by a topoisomerase-like transesterification reaction involving a covalent protein-DNA intermediate. With this knowledge as the backdrop, the role of Spo11 as the catalytic subunit for meiotic DSB formation was uncovered through two separate lines of inquiry. In one, sequencing of the genes for the first archaeal TopoVI revealed homology between the TopoVIA subunit and yeast Spo11 (Bergerat et al. 1997). The significance of this homology with respect to the biochemical function of Spo11 was immediately recognized and confirmed by genetic tests in S. cerevisiae (Bergerat et al. 1997). Separately, covalent protein-DSB complexes were purified from meiotic rad50S cells and the protein component was directly shown to be Spo11 (Keeney et al. 1997). 
Earlier genetic studies of SPO11 have been reviewed in detail (Keeney 2001). More recently, mutational analyses of $S$. cerevisiae Spo11 and the $S$. pombe ortholog Rec12 have confirmed the biochemical and structural similarity of Spo11 to the TopoVIA subunit (Diaz et al. 2002; Sharif et al. 2002; DeWall et al. 2005; Nag et al. 2006). In particular, residues have been identified in Spo11 and Rec12 that are equivalent to the catalytic tyrosine and acidic residues that coordinate a divalent metal ion in archaeal TopoVI. Also, TopoVIA is dimeric and forms hybrid active sites for DNA cleavage; each active site involves the CAP domain of one monomer and the Toprim domain of the other (Nichols et al. 1999). The semidominant phenotypes of $S$. cerevisiae spol1 mutants that lack key catalytic residues are consistent with the prediction that Spo11 has the same three-dimensional architecture (Diaz et al. 2002). When Spo11 proteins with different affinity tags are coexpressed, they can be coimmunoprecipitated, also consistent with formation of dimers or higher order oligomers (Sasanuma et al. 2007). Moreover, like TopoVI, Spo11 cleaves DNA to yield a twonucleotide 5' overhang (de Massy et al. 1995; Liu et al. 1995). The evidence in support of Spo11 as the catalyst for DSB formation is thus very strong. Direct biochemical demonstration of this activity in vitro has thus far proved elusive, however.

It is likely that an ancestral form of TopoVI evolved prior to the divergence of eukaryotic and archaeal lineages, and that with the evolution of meiosis and meiotic recombination the A subunit was subsequently adapted to perform a new function (Gadelle et al. 2003; Corbett and Berger 2004). Interestingly, there is no obvious equivalent of the B subunit of TopoVI in most eukaryotes, aside from some plants. Based on enzymatic and structural studies, the TopoVIB subunit is known or inferred to have several functions, some of which are dependent on binding and/or hydrolysis of ATP (Corbett and Berger 2003; Corbett and Berger 2004; Corbett and Berger 2005): 1) activating DNA cleavage by TopoVIA, presumably by influencing the position and orientation of the structural domain that contains the catalytic tyrosine; 2 ) inducing a conformational change that forces apart the TopoVIA subunits upon DNA cleavage; 3 ) providing a bridge that holds the two ends of the broken DNA together within the holoenzyme-DNA complex until the DNA duplex is resealed (see Figure 3). Although there is no reason to suspect that Spo11 carries out a strand passage reaction, Spo11 may perform a least a subset of the same or analogous catalytic steps and conformational changes during meiotic DSB formation as are performed by the TopoVIA subunit (discussed further in section 5). Thus, although it is possible that the functions performed by the TopoVIB subunit are not required for Spo11, it is also possible that some other protein(s) has been recruited to functionally replace the B subunit. One or more of the proteins in addition to Spo11 that are known to be required for DSB formation are excellent candidates (discussed in Section 3). If so, however, these proteins could presumably replace only ATP-independent functions of the B subunit, since none of these known proteins (except Rad50) has an ATP-binding motif.

Spo11 is highly conserved. The function of Spo11 orthologs in initiating meiotic recombination has been demonstrated in other fungi and in nematode, Drosophila, and mouse (Dernburg et al. 1998; McKim and Hayashi-Hagihara 1998; Baudat et al. 2000; Celerin et al. 2000; Romanienko and Camerini-Otero 2000; Steiner et al. 2002; Storlazzi et al. 2003; Bowring et al. 2006). Spo11 homologs have also been identified in plants, but in a genetically more complex arrangement than in many other organisms. Specifically, the $A$. thaliana genome encodes three genes homologous to SPO11, called AtSPO11-1, AtSPO11-2, and AtSPO11-3 (Hartung and Puchta 2000; Grelon et al. 2001; Hartung and Puchta 2001). Interestingly, both AtSPO11-1 and AtSPO11-2 are essential for initiation of meiotic recombination (Grelon et al. 2001; Stacey et al. 2006). How the products of these two genes work together to promote recombination is not yet clear, but it is tempting to speculate that DSBs in this organism are made by an obligate heterodimer of different Spo11-related subunits. AtSPO11-3 is dispensable for meiotic recombination, and instead 
encodes a protein that interacts with a homolog of TopoVIB to constitute a bona fide TopoVI relative (Hartung et al. 2002; Sugimoto-Shirasu et al. 2002; Yin et al. 2002; Sugimoto-Shirasu et al. 2005).

Spo11 appears to be present in all sequenced eukaryotic genomes, and indeed it may be the only truly universal meiotic protein (Ramesh et al. 2005) (S.-B. Malik and J. Logsdon, pers. commun.). Interestingly, Spo11 homologs are present even in lineages that are thought to be asexual and/or to not have a meiotic phase in their life cycles (Ramesh et al. 2005; Richard et al. 2005). The presence of Spo11 in the genome may signal the operation of cryptic sexuality in these species, not enough evolutionary time to lose the gene since the evolution of asexuality in the lineage, and/or retention of Spo11 because it has another function(s) aside from inducing meiotic recombination. Given the precedent of AtSPOI1-3, it is also possible that Spo11 homologs in some eukaryotes are TopoVI subunits rather than Spo11 orthologs, although thus far clear orthologs of the TopoVIB subunit have only been identified in higher plants.

In several fungi and in C. elegans, Spo11 expression is limited primarily or exclusively to meiotic cells (Atcheson et al. 1987; Lin and Smith 1994; Dernburg et al. 1998; Celerin et al. 2000; Storlazzi et al. 2003). However, in other organisms Spoll message has been detected in nonmeiotic cells, although no function for the gene has been demonstrated in these cases. In one example, Spo11 message was detected in mouse germinal center B cells undergoing immunoglobulin gene diversification and class switch recombination, but mice lacking Spol 1 had no detectable immune system defects (Klein et al. 2002). Another example is Drosophila, in which the Spoll homolog meiW-68 is expressed in testis (where no meiotic recombination occurs) and in somatic cells of embryos and pupae (McKim and HayashiHagihara 1998; Lankenau 2006).

The association of Spo11 with meiotic chromosomes has been analyzed in several organisms. Cytological studies showed Spo11 forming discrete staining structures ("foci") on chromatin as early as leptonema in mouse, Sordaria macrospora, and S. cerevisiae (Romanienko and Camerini-Otero 2000; Storlazzi et al. 2003; Prieler et al. 2005). This is the period when DSBs are formed, so these cytologically visible Spo11 complexes are present at the right time to be involved in DSB formation. Somewhat surprisingly, however, Spo11 persists on chromosomes into the pachytene stage in each of these organisms, past the time of DSB generation. As discussed below, similar behavior is seen for the other yeast DSB proteins; it is not yet known whether this persistent association with chromosomes has a function, and if so, what that function might be.

Chromatin immunoprecipitation (ChIP) has provided an even more detailed picture of Spo11 binding to chromatin in S. cerevisiae, and has demonstrated a preferential association of Spo11 with at least some DNA sequences where DSBs frequently form (i.e., DSB hotspots) (Prieler et al. 2005). The ChIP study by Klein and colleagues revealed a particularly intriguing aspect of Spo11 binding to chromatin (Prieler et al. 2005). In rad50S mutants at relatively late time points, covalent association of Spo11 with hotspots could be detected without the need to crosslink with formaldehyde, as expected since Spo11 remains covalently bound to DSB ends in this mutant. Surprisingly, however, Spo11 binding to hotspots could also be detected without crosslinking at earlier time points, prior to the formation of DSBs. This "tight" binding could be disrupted with high salt, and the strands of the Spo11-associated DNA were intact, so Spo11 was not covalently linked to the DNA in these complexes. Importantly, these complexes were not seen in wild-type cells, and they formed in the rad50S mutants at the same time that DSBs would have appeared in wild type (the rad50S DSBs were slightly delayed)2. Prieler et al. have proposed that these "tight" Spo11-DNA complexes are an intermediate in the normal DSB pathway in which Spo11 has 
been activated in some way. Their findings may have important implications for understanding the mechanism of DSB formation as well as for understanding the nature of the defect in rad50S mutants. These issues are discussed further in Section 5.

\subsection{Formation and Early Processing of Spo11-Dependent DSBs}

Extrapolating from the structure of the TopoVIA subunit provides a detailed picture of what Spo11 might look like as it cleaves DNA (Figure 4). Binding of a Spo11 dimer to DNA would position the metal binding pocket of each monomer close to the scissile bond on one of the strands of the duplex (Figure 4a). The catalytic tyrosine residue of one monomer (Tyr-135 in S. cerevisiae Spo11) interacts with the metal binding pocket on the other monomer. Two hybrid active sites are thus formed on either side of the duplex3.

Nucleophilic attack by the tyrosine residues cleaves the DNA strands and generates a DSB with Spo11 covalently attached to the $5^{\prime}$ strand termini. If the dimer interface were to be disrupted at this point (as cartooned in Figure 4b), the ends of the DSB would also be separated as in the strand passage gate opened in TopoVI (see Figure 3).

Recent work in S. cerevisiae and mouse has demonstrated that Spo11 is removed from DSB ends by an endonucleolytic mechanism in which nicks are introduced into the Spo11-bound strands adjacent to the DSB (Figure 4b) (Neale et al. 2005). This reaction releases Spo11 still covalently bound to a short oligonucleotide. Presumably, the nicks serve as starting points for further $5^{\prime} \rightarrow 3^{\prime}$ exonucleolytic processing. The endonuclease activity of Mre11 is an excellent candidate for clipping off Spo11 (see Section 3.1). The exonuclease responsible for more extensive end resection is not yet known, although Exo1 may play a role (reviewed in Hunter 2007).

Spo11-associated oligonucleotides are heterogeneous in length and in S. cerevisiae they fall into two discrete size classes of roughly equal abundance: about half of the oligonucleotides are 7-12 nucleotides in length, and the remainder are 21-37 nucleotides (Neale et al. 2005). How these two populations arise is not yet known, but they have been proposed to result from asymmetric spacing of the nicks on either side of the DSB. In any case, the shorter oligonucleotides would be derived from cleavage at the edge of the protein-DNA footprint predicted from the TopoVIA structure, whereas the longer oligonucleotides would result from cleavage several turns of the helix away (Figure 4b). Because of the twonucleotide 5' overhang of the DSB, the shorter oligonucleotides would only form 5-10 bp of duplex which might be readily disrupted in vivo. In contrast, the longer oligonucleotides would need to be actively unwound from the 3 '-terminal strand. These considerations have suggested a model in which one side of the DSB ends in a free $3^{\prime}$ strand whereas the other side is capped because it remains base-paired to the Spo11-associated oligonucleotide (Figure 4c) (Neale et al. 2005). Such an asymmetric structure might dictate the asymmetric behavior of the two ends of the DSB in which one end invades a homologous duplex and the other DSB end is captured in a second reaction (Figure 1).

Unless the covalently bound oligonucleotide can be removed, Spo11 would be irreversibly consumed when it makes a DSB. It has been speculated that this suicide mechanism might be a means of limiting the numbers of DSBs (Keeney et al. 1997), but in fact there is considerably more Spo11 protein in the cell than what catalyzes DSB formation (Neale et al.

\footnotetext{
2It has also been demonstrated that DSBs in rad50S and sae2 mutants have a different broad-scale distribution than DSBs in wild type cells (Dresser et al. 1997; Borde et al. 2000). In particular, DSBs that normally form in late-replicating portions of chromosomes (e.g., near telomeres) are specifically reduced or absent in rad50S and sae 2 mutants (Borde et al. 2000). These findings provide further evidence that rad50S DSBs are not simply "normal" breaks that cannot be repaired.

${ }^{3}$ Whether Spo11 dimerizes on the DNA or is dimeric in solution, as is TopoVIA (Nichols et al. 1999), remains to be determined (see Sasanuma et al. 2007).
} 
2005). Moreover, Spo11 persists on chromatin and at hotspots well past the time of DSB formation (Romanienko and Camerini-Otero 2000; Storlazzi et al. 2003; Prieler et al. 2005). These observations raise the question of what, if anything, the "extra" Spo11 does: is there a function other than making DSBs? More importantly, these results indicate that binding of Spo11 to DNA is not sufficient to make a DSB, but rather that Spo11 must be activated in some way (Prieler et al. 2005). Subsequent sections will discuss some of the ways that this activation might occur and how it is controlled.

\section{Other Proteins Required for Meiotic DSB Formation4}

\subsection{DSB Proteins in S. cerevisiae}

Spo11 is the catalytic center of the meiotic recombination initiation mechanism, but it is not sufficient to generate DSBs: numerous additional proteins are also required. In $S$. cerevisiae, at least nine other proteins are essential for Spo11 activity. Increasing detail is emerging about the interactions among these proteins, but their precise functions are not yet well understood.

Ski8-Ski8 (also nknown as Rec103) is particularly intriguing because it has two very distinct physiological roles: during meiosis, it is required for DSB formation (Gardiner et al. 1997; Tessé et al. 2003), but in vegetative cells it is involved in RNA metabolism. Ski8 forms a cytoplasmic complex with Ski2 and Ski3 (Brown et al. 2000; Wang et al. 2005) that is required for inhibition of translation of nonpolyadenylated RNA and for $3^{\prime} \rightarrow 5^{\prime}$ exonucleolytic degradation of RNA (Masison et al. 1995; Jacobs Anderson and Parker 1998; van Hoof et al. 2000; Araki et al. 2001). During meiosis, however, Ski8 relocalizes from the cytoplasm to the nucleus and associates with meiotic chromosomes, dependent on Spo11 in both S. cerevisiae and S. macrospora (Tessé et al. 2003; Arora et al. 2004). S. cerevisiae Ski8 interacts with Spo11 in two-hybrid assays, and point mutations in Spo11 that disrupt this interaction also eliminate DSB formation (Arora et al. 2004). It thus appears that Ski8 is a direct partner of Spo11 and that interaction between the two proteins is essential for DSB formation. Ski8 is required for association of Spo11 with chromosomes in S. macrospora (Tessé et al. 2003). The same is not true in S. cerevisiae (Prieler et al. 2005), but bulk chromatin fractionation assays indicate that binding of Spo11 to chromatin is at least partially reduced in the absence of Ski8 (Arora et al. 2004). A Ski8 ortholog, Rec14, is required for meiotic DSBs in S. pombe (Evans et al. 1997; Fox and Smith 1998; Davis and Smith 2001; Molnar et al. 2003), but the role of Ski8 in promoting Spo11 activity does not appear to be universal since the Arabidopsis homolog is not required for meiotic recombination (Jolivet et al. 2006).

Ski8 is a member of the WD repeat family of proteins, and crystallographic studies revealed that Ski8 has the toroidal $\beta$-propeller structure characteristic of this family (Cheng et al. 2004; Madrona and Wilson 2004). It is straightforward to think that, like other known WD proteins, Ski8 bridges interactions between other proteins. Studies in S. cerevisiae are consistent with this hypothesis: Ski8 is required in order for Spo11 to interact with Rec104 in two-hybrid assays (Arora et al. 2004). However, this begs the question, why are these bridging interactions important for Spo11 to cleave DNA? Moreover, it is not yet known whether Ski8 does something during meiosis in addition to bringing together Spo11 and other proteins.

\footnotetext{
${ }^{4}$ This section focuses on the subset of proteins thought to be most directly involved in promoting Spo11-dependent DSB formation. Not considered here are numerous other factors that are required for DSBs, but which are known or suspected to be more indirectly involved. These include regulatory factors that control the decision to enter meiosis and transcription factors that control expression of Spo11 or other meiotic recombination proteins.
} 
Mre11-Rad50-Xrs2 (MRX)-These proteins form an evolutionarily conserved complex with multiple roles in many different aspects of DNA metabolism, including DNA repair, telomere maintenance, and checkpoint signaling. Mre11 has single-strand endonuclease and $3^{\prime} \rightarrow 5^{\prime}$ exonuclease activities and Rad50 is an ATP-binding protein structurally related to SMC proteins. The structure and functions of these proteins have been reviewed in detail (Assenmacher and Hopfner 2004; Krogh and Symington 2004; Stracker et al. 2004). I will focus here on their roles in meiosis.

The MRX complex is required for DSB formation in S. cerevisiae: a null mutation in any of the genes completely eliminates meiotic recombination (reviewed in Keeney 2001). The complex is also required to process the DSBs once they are formed: specific rad50 and mre 11 point mutations (generally called rad50S and mre $11 S$ mutations) cause DSBs to accumulate with Spo11 covalently attached to the DNA ends. Deletion of the SAE2/COM1 gene causes the same phenotype (Keeney and Kleckner 1995; McKee and Kleckner 1997; Prinz et al. 1997). These mutants all share other defects in telomere maintenance and in processing of hairpin DNA ends, consistent with the hypothesis that they share a common biochemical defect (Assenmacher and Hopfner 2004; Krogh and Symington 2004; Stracker et al. 2004). Since mrel1 mutants in this class include mutants known to eliminate the protein's endonuclease activity (Furuse et al. 1998; Moreau et al. 1999), it is reasonable to argue that Mre11 endonuclease is essential for the processing of DSB ends in meiosis, and in particular for endonucleolytic removal of Spo11 from DSB ends (section 2.3) (Neale et al. 2005). However, it is not yet clear why MRX is required for formation of DSBs and not just for DSB processing. One possibility is that the requirement for the presence of MRX facilitates close coordination of DSB formation with subsequent processing of the DSB ends (Borde et al. 2004). Such coordination may help ensure that potentially lethal DSBs are repaired efficiently.

Mre11 is required for both formation and repair of DSBs in C. elegans, as in budding yeast (Chin and Villeneuve 2001). In contrast, MRX orthologs are not required for DSB formation in S. pombe, the mushroom Coprinus cinereus, or Arabidopsis, although they are required for normal repair of meiotic DSBs in all organisms tested (Gerecke and Zolan 2000; Merino et al. 2000; Bleuyard et al. 2004; Puizina et al. 2004; Young et al. 2004). Moreover, in S. pombe, a rad50S-like mutation and a nuclease-defective allele of rad32 (the ortholog of MRE11) both confer defects in meiotic DSB repair (Farah et al. 2002; Steiner et al. 2002; Young et al. 2002; Farah et al. 2005b). Thus, it appears that the role of MRX in processing DSB ends is evolutionarily conserved, even if the role in promoting DSB formation is not. It has not been possible to address whether members of the complex are required for DSB formation in mouse because null mutations for any of these factors are lethal (Xiao and Weaver 1997; Luo et al. 1999; Zhu et al. 2001). A targeted Rad50 mutation in mouse (changing Lys-22 to Met, mimicking an S. cerevisiae rad50S point mutation) recapitulates the checkpoint hyperactivation phenotype of the yeast mutant, but not the meiotic DSB processing phenotype (Bender et al. 2002; Morales et al. 2005; Usui et al. 2006). However, the corresponding point mutation in yeast (Arg-20 to Met) has a relatively weak phenotype (Alani et al. 1990), and a mimic of a stronger yeast allele does not support growth of mouse embryonic stem cells in culture (Bender et al. 2002), so the question of whether the Mre11 complex processes meiotic DSBs in mammals also remains unanswered.

Several functional subdomains of the MRX proteins important for meiotic recombination have been defined. As mentioned above, the Mre11 nuclease activity is required for Spo11 to be removed from DSB ends. Additionally, the C-terminal region of S. cerevisiae Mre11 is required for DSB formation and interacts with as-yet-unknown meiosis-specific proteins (Usui et al. 1998). This domain may not be conserved, however, as mutations that affect the C terminus of mouse MRE11 do not block meiotic DSB formation (Theunissen et al. 2003). 
Rad50, as a member of the SMC family, has N- and C-terminal globular domains that come together to form a module for ATP-dependent dimerization and DNA binding (Hopfner 2006). These domains are separated by stretches of heptad repeat sequence that fold back to form a long alpha-helical coiled coil. One end of this coiled coil lies at the ATP binding domain, while the other end has a zinc-hook structure that allows multimerization of MRX complexes (Hopfner et al. 2002). Both ATP binding and zinc-hook driven multimerization are essential for DSB formation (Alani et al. 1990; Wiltzius et al. 2005).

The amino acid sequence of Xrs2 is less well conserved than the other members of the complex, although at least some functional domains are conserved. Xrs2 and its human equivalent NBS1 have N-terminal FHA and tandem BRCT domains (Chahwan et al. 2003; Becker et al. 2006), which are motifs often involved in binding to phosphopeptides (Durocher and Jackson 2002; Glover et al. 2004). S. cerevisiae Xrs2 also has conserved Cterminal domains required for interaction with Mre11 and with the kinase Tel1 (Shima et al. 2005; Tsukamoto et al. 2005). The Mre11-interaction domain is required for DSB formation, but the Tel1-interaction domain is not (Shima et al. 2005; Tsukamoto et al. 2005). Xrs2 also interacts with Mer2 in two-hybrid assays, and this interaction requires a serine residue on Mer2 that is phosphorylated by cyclin-dependent kinase (CDK) (see below). It is tempting to speculate that the putative phosphoserine-binding tandem BRCT motif on Xrs2 mediates interaction with phosphorylated Mer2. Indeed, deletion mutations affecting this region in Xrs2 do cause defects in forming and/or repairing DSBs, although this portion of Xrs2 is not essential for these processes (Shima et al. 2005; Tsukamoto et al. 2005).

In genome-wide ChIP analyses, S. cerevisiae Mre11 bound preferentially to sites of DSB formation, and association with hotspots required all of the DSB proteins except, surprisingly, Rad50 (Borde et al. 2004). Rad50 was also associated with hotspots by ChIP, but this association required both Mre11 and Xrs2. In rad50S or sae2 $\Delta$ mutants, Mre11 ChIP signal persisted at DSB sites in time course experiments, suggesting that the protein remains associated with unresected DSBs (Borde et al. 2004). Persistent accumulation at unresected DSBs could also be detected cytologically as discrete immunostaining foci of MRX proteins on chromosomes (Usui et al. 1998). The specific localization to DSB sites strongly supports the hypothesis that the MRX complex is a direct player in DSB formation and resection.

Rec102-Rec104-The meiosis-specific Rec102 and Rec104 proteins interact genetically and physically in a variety of assays (Salem et al. 1999; Kee and Keeney 2002; Jiao et al. 2003; Kee et al. 2004). Both proteins localize to the nucleus and are associated with meiotic chromosomes starting as early as leptonema, and both continue to accumulate as meiotic prophase progresses before abruptly dissociating from chromatin at mid-pachynema (Kee et al. 2004). They require each other and also Spo11 and Ski8 (but not other DSB proteins) for nuclear localization and for binding to chromatin (Kee et al. 2004). Rec102 and Rec104 are both required for Spo11 to self-associate, to bind to chromatin, to localize to DSB hotspots (Prieler et al. 2005; Sasanuma et al. 2007). ChIP and immunocytological analyses indicated that Rec102 binds preferentially to chromatin loops (as opposed to the chromosome axes), but the protein is associated with both DSB-hot and DSB-cold domains, so its presence cannot be sufficient to specify where DSBs will occur (Kee et al. 2004). Rec104 is phosphorylated during meiosis, and normal phosphorylation patterns require Rec102 but not DSB formation (Kee et al. 2004). The kinase(s) responsible has not been identified, nor is it yet known whether this phosphorylation is required for DSB formation. The close congruence in behaviors of Rec102 and Rec104 strongly suggests that these proteins are a functional unit, and two-hybrid, coimmunoprecipitation, and genetic interactions connect them closely with the Spo11-Ski8 complex (Kee and Keeney 2002; Jiao et al. 2003; Arora et al. 2004). However, they lack identifiable sequence motifs and the available data do not 
reveal specific biochemical activities, so precisely what roles they play in DSB formation remains to be determined.

Mer2-The cyclin-dependent kinase Cdc28 and its B-type cyclin partners Clb5 and/or Clb6 are required for early events in meiosis, including meiotic DNA replication and initiation of recombination (Stuart and Wittenberg 1998; Smith et al. 2001; Benjamin et al. 2003).

Recent studies point to Mer2 (also known as Rec107) as a conduit for CDK-dependent regulatory signals controlling DSB formation (Henderson et al. 2006). Mer2 is phosphorylated during meiosis in a CDK/Clb5/Clb6-dependent manner and can be directly phosphorylated by CDK in vitro. One of two CDK target sites on Mer2 protein (Ser-30) is essential for recombination: mutation of this residue to alanine abrogates DSB formation, apparently by altering or eliminating interactions of Mer2 with other DSB proteins (Henderson et al. 2006). It has been proposed that regulation of Mer2 activity by CDK is part of the mechanism that coordinates DSB formation with progression through meiosis. Additional processes that regulate DSB formation are discussed in Section 4.

The biochemical function of Mer2 is not clear, however. There are no known homologs of Mer2 in organisms aside from other closely related yeast species (Henderson et al. 2006), and no obvious structural motifs aside from a short stretch of heptad repeat sequence (Rockmill et al. 1995). In two-hybrid analyses, Mer2 interacts with itself, Mei4, Xrs2, and Rec114 (Arora et al. 2004). All of these interactions appear to be influenced at least partially by CDK-dependent phosphorylation of Mer2 (Henderson et al. 2006). Mer2 localizes to discrete foci on meiotic chromosomes prior to DSB formation and neither CDK-dependent phosphorylation nor any of the other DSB proteins are required for Mer2 to associate with chromatin (Henderson et al. 2006; Li et al. 2006).

The expression of Mer 2 is controlled in an unusual manner. The message is constitutively expressed but has an intron that is inefficiently spliced because of a noncanonical 5' splice site and because the $5^{\prime}$ exon is much longer than is typical in yeast (Nandabalan et al. 1993; Nandabalan and Roeder 1995). A meiosis-specific splicing factor, Mer1, binds to a splicing enhancer sequence within the MER2 intron (Engebrecht et al. 1991; Nandabalan et al. 1993; Nandabalan and Roeder 1995; Spingola and Ares 2000). Mer1 collaborates with other splicing factors including Bud13, Nam8, and U2 snRNP protein Snu17 to increase MER2 mRNA splicing efficiency (Nakagawa and Ogawa 1997; Spingola and Ares 2000; Spingola et al. 2004; Scherrer and Spingola 2006). The amount of full-length Mer2 protein is thus substantially upregulated in meiosis even though total message levels only increase $\sim 2$-fold (Chu and Herskowitz 1998; Henderson et al. 2006; Li et al. 2006)5.

The protein is not completely meiosis-specific, however. The basal splicing efficiency of reporter mRNA constructs is $~ 15-20 \%$ in the absence of Mer1 (Spingola and Ares 2000; Scherrer and Spingola 2006). As a consequence, full-length Mer2 protein is also present in vegetative cells, where it associates with chromatin in discrete foci (Henderson et al. 2006; $\mathrm{Li}$ et al. 2006). Moreover, the unspliced MER2 message encodes a 131 amino acid polypeptide containing 105 of the 314 residues of the full-length protein, including one of the known CDK target sites. It is not yet known whether significant amounts of truncated

\footnotetext{
${ }^{5}$ The splicing of mRNA from two other genes, MER3 and SPO70/AMA1 is also regulated by Mer1 (Nakagawa and Ogawa 1999; Davis et al. 2000). Mer3 is a DNA helicase required for normal meiotic recombination (Nakagawa and Ogawa 1999; Mazina et al. 2004) and Ama1 is a meiosis-specific component of the cell cycle regulator, the anaphase promoting complex (Cooper et al. 2000). It is not clear why these three genes share this unusual means by which their expression is controlled. More recently, it has been demonstrated that RNA from most, if not all, of the meiotic genes that contain introns are inefficiently spliced in vegetative cells, including the transcriptionally repressed DSB genes REC102, MEI4, and REC114 (Juneau et al. 2007). Splicing efficiency of these genes is significantly increased in meiotic cells. The mechanism for this regulation is not understood, but is likely to be distinct from Mer1-dependent splicing control.
} 
protein are made from this message and, if so, whether it has a function (although a cDNA version of MER2 lacking the intron fully suppresses the DSB defect of a mer2 $\triangle$ mutant (Engebrecht et al. 1991)). The unspliced message is exported from the nucleus and is a target for nonsense-mediated decay (He et al. 2003; Scherrer and Spingola 2006).

Rec114, Mei4-Relatively little is known about the behaviors and functions of the meiosis-specific Rec114 and Mei4 proteins. They can be grouped together with Mer2 based on two-hybrid and coimmunoprecipitation analyses that reveal interactions between them as well as immunocytological studies that show that they colocalize with one another on meiotic chromosomes (Arora et al. 2004; Henderson et al. 2006; Li et al. 2006)(Maleki et al., submitted). Cytological experiments further indicate that these proteins form complexes that are distinct from those containing Spo11 and Rec102 (Li et al. 2006). Rec114, Mei4, and Mer2 still associate with chromatin in the absence of the other proteins, although Mei4 binding to chromosomes is reduced in mer $2 \Delta$ ( $\mathrm{Li}$ et al. 2006). Rec114 is required for Spo11 and Mre11 association with hotspot sequences as assessed by ChIP and for Spo11 selfassociation as measured by coimmunoprecipitation, but not for binding of Spo11 to chromatin in cytological studies of spread chromosomes (Borde et al. 2004; Prieler et al. 2005; Sasanuma et al. 2007). Rec114 overexpression suppresses DSB formation, suggesting that the balance of the amount of Rec114 relative to other factors is critical (Bishop et al. 1999). Rec114 shares limited sequence homology with the Rec7 protein of $S$. pombe (Malone et al. 1997; Molnar et al. 2001) (see Section 3.2). No homologs of Mei4 are known outside of species closely related to $S$. cerevisiae (Richard et al. 2005). (The S. pombe Mei4 protein is not related by sequence or function to $S$. cerevisiae Mei4.)

What do the DSB proteins do?-While there has been significant progress in understanding the behaviors of the $S$. cerevisiae DSB proteins and the interactions among them, no clear picture of their precise roles has yet emerged. Functions could include targeting Spo11 binding to specific sites, activating Spo11 catalytic activity (Section 2.3), and/or coordinating DSB formation with chromatin and higher order chromosome structure (see Section 4). Interestingly, most of the DSB proteins are capable of targeting Spo11 activity to new locations when they are fused to a sequence-specific DNA binding protein such as Gal4 (A. Nicolas, pers. commun.). However, it is not yet known whether such targeting is a physiological role for any of the DSB proteins.

It is also not yet known how these proteins work together to promote DSB formation. It is possible that they are stoichiometric subunits of a discrete DSB-forming holoenzyme. However, many of the recent studies seem inconsistent with this hypothesis. For example, as discussed above, it appears that Rec102 and Rec104 interact to form a single functional unit and, although this putative Rec102-Rec104 complex interacts with other DSB proteins, there are numerous differences between Rec102-Rec104 and the other proteins with respect to their genetic dependencies for protein-protein and protein-chromosome interactions. Similarly, differences in localization, interactions, and functional dependencies distinguish many of the DSB proteins from one another (Kee et al. 2004; Prieler et al. 2005; Li et al. 2006). These studies do not rule out the existence of a distinct DSB-forming holoenzyme, but the emerging picture does support the idea that instead there there are distinct functional entities that collaborate to make a DSB. An important challenge now is to understand how these subgroups of proteins (Spo11-Ski8, Rec102-Rec104, Mei4-Mer2-Rec114, and Mre11Rad50-Xrs2) work together and how they are recruited to the sites where DSBs form.

Evolutionary conservation and divergence-Spo11 orthologs are readily identifiable in widely diverged species because of conservation of core structural domains essential for catalytic activity, but the protein sequence overall is not very well conserved (Keeney 2001; Gadelle et al. 2003) (Figure 5). Many of the other DSB proteins are conserved even less 
well. Even for yeasts closely related to $S$. cerevisiae, the meiosis-specific DSB proteins have diverged rapidly while (presumably) retaining their functions in DSB formation (Figure 5) (Richard et al. 2005). For example, Rec114 homologs in S. cerevisiae and the very closely related species Saccharomyces paradoxus share only $73.4 \%$ amino acid identity (Malone et al. 1997 and our unpublished observations). In contrast, nucleotide sequence across all coding regions in these species is $>88 \%$ identical and $\sim 65 \%$ of proteins have $\geq 90 \%$ amino acid identity (Cliften et al. 2001). Indeed, it appears that proteins involved in meiotic recombination are generally among the more rapidly diverging of all cellular proteins (e.g., Ramesh et al. 2005; Richard et al. 2005). In part because of this divergence, it has been difficult (or impossible) to identify clear homologs of many of the DSB proteins in organisms other than those closely related to $S$. cerevisiae. However, forward genetic screens for recombination mutants have uncovered a number of additional DSB factors in several other organisms. These are summarized in Sections 3.2 and 3.3 below. Examples of conserved DSB proteins were discussed along with their S. cerevisiae counterparts above (e.g., Spo11 in many organisms; Ski8 in S. pombe and S. macrospora).

For the proteins that are conserved poorly or not at all, it is possible that there are no equivalents in some organisms or that other proteins are functional substitutes. It is also possible that there has been structural and functional conservation despite insufficient sequence conservation to allow ready identification. However, it is becoming increasingly clear that there are likely to be significant mechanistic differences between organisms, as revealed by the fact that some proteins whose sequences are conserved are not conserved functionally. For example, as noted above, orthologs of Rad50, Mre11, and Xrs2 are not required for DSB formation in S. pombe, C. cinereus, or A. thaliana, although they are required for processing of meiotic DSBs (Gerecke and Zolan 2000; Merino et al. 2000; Bleuyard et al. 2004; Puizina et al. 2004; Young et al. 2004). Similarly, whereas Ski8 orthologs are required for DSB formation in S. cerevisiae, S. pombe, and S. macrospora, the Ski8 ortholog in A. thaliana is dispensable for meiosis (Jolivet et al. 2006). In these examples, it may be that the functions performed in DSB formation in some organisms are performed by different proteins in other species, or that the biochemical functions themselves are only required in certain organisms.

\subsection{DSB Proteins in S. pombe}

Numerous proteins required for DSB formation in S. pombe have been identified in addition to Rec12 (the Spo11 ortholog) and Rec14 (Ski8 ortholog). Some of these proteins are conserved, but, as for $S$. cerevisiae, many have no clear homologs in other organisms. Earlier literature on meiotic recombination in $S$. pombe has been reviewed in detail (Fox and Smith 1998; Davis and Smith 2001; Young et al. 2004).

Rec7-The $\operatorname{rec}^{+}$gene was uncovered in a forward genetic screen for meiotic recombination defects (Ponticelli and Smith 1989; De Veaux et al. 1992) and subsequently shown to be required for DSB formation (Cervantes et al. 2000; Davis and Smith 2001). Expression of $\mathrm{rec}^{+}$is induced in meiosis (Lin et al. 1992), and the protein localizes to nuclei and associates with meiotic chromosomes in up to $\sim 40$ discrete foci that have been proposed to represent sites of recombination initiation (Molnar et al. 2001; Lorenz et al. 2006). The $38.2 \mathrm{kDa}$ protein shares sequence in its N-terminal region with Rec114 (Malone et al. 1997; Molnar et al. 2001), suggesting that these are orthologs.

Mde2, Rec6, Rec15, Rec24, Rec25, Rec27-The rec6 ${ }^{+}$and $r e c 15^{+}$genes were identified in the same screens that yielded mutations in $\mathrm{rec}^{+}, \mathrm{recl}^{+}$, and $\mathrm{recl} 4^{+}$(Ponticelli and Smith 1989; De Veaux et al. 1992). Expression of both is up-regulated in meiosis (Lin and Smith 1994; Lin and Smith 1995), and both are required for DSB formation (Cervantes 
et al. 2000; Davis and Smith 2001). A function for Rec15 before recombination initiation is suggested by the observation that early meiotic events (including onset of replication) occur earlier than normal in rec15 mutants (Doll et al. 2005). The molecular nature of this potential early function has not yet been reported, however. Roles for the $m d e 2^{+}$("Mei4dependent"), rec $24^{+}$, rec $25^{+}$, and $r e c 27^{+}$genes in DSB formation were uncovered in screens involving systematic deletion of previously uncharacterized genes whose expression is upregulated in meiosis (Gregan et al. 2005; Martin-Castellanos et al. 2005). All six genes discussed in this section encode small proteins (15.8-40.2 kDa) with no clear homologs in other species and no obvious motifs to suggest biochemical function. Important next steps in understanding the mechanism of DSB formation in S. pombe include detailed characterization of the behaviors of these proteins, including testing for chromosomal localization and interactions among them.

Rec8, Rec10, Rec11-Fission yeast does not form synaptonemal complexes, but instead forms filamentous structures called linear elements, which resemble the axial cores of chromosomes in other organisms (reviewed by Loidl 2006). Rec10 is a meiosis-specific protein that localizes to linear elements in immunofluorescence analysis (Lorenz et al. 2004) and is required for linear element formation as assessed by electron microscopy (Molnar et al. 2003). Complete deletion of the $\mathrm{rec} 10^{+}$coding region confers a phenotype indistinguishable from a rec12 mutation, thus Rec10 is essential for all DSB formation (Ellermeier and Smith 2005). A rec10 mutant (rec10-155) has been described which does not form linear elements but which does make DSBs, thus indicating that linear elements themselves are not essential for DSBs (Wells et al. 2006). Rec7 foci are closely associated with Rec10-staining linear elements, and these foci do not form in rec 10 mutants (Lorenz et al. 2006). Based on these and other observations, it has been suggested that Rec10 recruits Rec7 to chromosomes, although it remains to be determined whether these proteins interact directly, and whether Rec10 is required for recruitment of other DSB proteins to chromosomes as well (Ellermeier and Smith 2005; Lorenz et al. 2006).

Rec8 and Rec11 are meiosis-specific cohesin components that assemble on chromosomes around the time of premeiotic DNA replication (Watanabe and Nurse 1999; Kitajima et al. 2003). DSB formation and meiotic recombination are greatly reduced in the absence of either of these proteins. However, the magnitude of the recombination decrease varies substantially depending on the genomic region assayed, ranging from $\sim 4$-fold to $>100$-fold (DeVeaux and Smith 1994; Krawchuk et al. 1999; Parisi et al. 1999; Ellermeier and Smith 2005). These mutants form aberrant linear elements as assessed by electron microscopy and Rec10 immunostaining (Molnar et al. 1995; Molnar et al. 2003; Lorenz et al. 2004), and numbers of Rec7 foci are reduced in rec $8 \Delta$, consistent with the partial DSB defect (Lorenz et al. 2006). One interpretation of these findings is that the involvement of Rec8 and Rec11 in the loading of Rec7 and perhaps other DSB components is indirect, through formation of Rec10-containing linear elements (Ellermeier and Smith 2005). It has furthermore been suggested that the low level DSB formation in rec 8 and recll mutants is promoted by the presence of residual mitotic cohesin containing Rad21 and Psc3, which are paralogs of Rec8 and Rec11, respectively (Ellermeier and Smith 2005). Interestingly, the regional variation in the $r e c 8$ and rec 11 recombination defects is similar to what is seen with a rec 10 missense mutation (rec10-109), leading to the suggestion that this mutant is specifically defective in Rec8-dependent but not Rad21-dependent DSB formation (DeVeaux and Smith 1994; Ellermeier and Smith 2005).

Rec10 is homologous to S. cerevisiae Red1 (Lorenz et al. 2004), which similarly localizes to and is required for formation of axial cores (Rockmill and Roeder 1988; Smith and Roeder 1997). Red1 is required for normal DSB formation in S. cerevisiae, but this requirement is not absolute as for Rec10 in S. pombe (Xu et al. 1997). Rec8 is also conserved in $S$. 
cerevisiae, but is largely if not completely dispensable for DSB formation in that organism (Klein et al. 1999). Thus, while DSB formation is coordinated with development of higher order chromosome structure in both yeast species (see also Section 4.5 below), the molecular details of this coordination appear to differ significantly.

\subsection{DSB Proteins in Larger Eukaryotes}

The pattern of relatively poor conservation of DSB proteins is even more pronounced moving from fungi to multicellular eukaryotes, where no orthologs are known for most of the budding and fission yeast DSB proteins aside from Spo11. Forward genetic screens in several organisms have uncovered novel proteins required for DSB formation. To date, there are no reported budding or fission yeast orthologs for these proteins and, given the complexity of the DSB forming machinery in yeasts, it is likely that many more genes remain to be uncovered.

D. melanogaster MEI-P22-A mei-P22 mutation was recovered in a screen for Pelement insertions that cause meiotic chromosome missegregation (McKim et al. 1998; Sekelsky et al. 1999). The mutant eliminated gene conversion, crossing over, and recombination nodule formation (McKim et al. 1998), phenotypes that are indistinguishable from those of mutations eliminating the Spo11 ortholog MEI-W68 (McKim et al. 1998; McKim and Hayashi-Hagihara 1998). Direct assays for DSBs are not yet available for Drosophila. However, convincing evidence that MEI-P22 is required for DSB formation is provided by observations that strong mei-P22 mutations: a) eliminate formation of $\gamma$ His2Av, the Drosophila equivalent of $\gamma \mathrm{H} 2 \mathrm{AX}$; b) suppress the sterility phenotype caused by mutations that affect the repair of DSBs; and c) can in turn be partially suppressed by Xirradiation (Liu et al. 2002; Jang et al. 2003; Mehrotra and McKim 2006). MEI-P22 is a basic, 35.7-kDa protein with no obvious homologs or structural motifs. The protein localizes to meiotic chromosomes and forms discrete foci prior to appearance of $\gamma$-His2Av (Liu et al. 2002; Mehrotra and McKim 2006).

C. elegans HIM-17-Null mutations in him-17 cause recombination defects similar to spo-11 mutants in this organism, including defects in chiasma formation, chromosome missegregation, and failure to accumulate RAD-51 foci, and, as for spo-11 mutants, these defects are suppressed by introduction of radiation-induced DNA damage (Reddy and Villeneuve 2004). HIM-17 protein has six repeats of a sequence motif found in P-element transposase and a number of other proteins (Reddy and Villeneuve 2004); this motif is implicated in DNA binding (e.g., Clouaire et al. 2005), and indeed HIM-17 is chromosomeassociated (Reddy and Villeneuve 2004). A role for this protein in post-translational histone modifications is also indicated, because him-17 null mutants show reduced and delayed accumulation of histone $\mathrm{H} 3$ dimethyl lysine 9 . This defect is not seen in spo-11 mutants, so this is not simply a consequence of failing to make DSBs (Reddy and Villeneuve 2004). How HIM-17 functions in DSB formation is not yet clear, however, and it remains to be determined whether its roles in histone modifications and DSB formation are related.

Mouse MEl1—Schimenti and colleagues undertook a forward genetic screen for fertility mutants in mice, using chemical mutagenesis of animals or of embryonic stem cells (Ward et al. 2003). One of the fertility mutants uncovered in this screen is defective for the Meil gene (Libby et al. 2002; Libby et al. 2003). Meil mutations confer phenotypes indistinguishable from Spol1 mutants in this organism, including chromosome synapsis defects, achiasmate chromosomes in oocytes, absent or reduced formation of RAD51 foci and $\gamma \mathrm{H} 2 \mathrm{AX}$, and suppression of specific meiotic phenotypes caused by defects in the repair of DSBs (i.e., epistasis to a Dmcl mutation) (Libby et al. 2002; Libby et al. 2003; Reinholdt and Schimenti 2005). Meil expression is highly restricted to gonads, and likely orthologs are 
present in other vertebrates (Libby et al. 2003). Interestingly, MEII sequence polymorphisms in human may be associated with some cases of azoospermia caused by meiotic arrest (Sato et al. 2006). A potential Meil homolog has also been found in Arabidopsis (Grelon et al. 2003), but homologs are apparently not present in flies, worms, or fungi (Libby et al. 2003). The biochemical function of the protein in DSB formation remains to be determined.

A. thaliana SWI1-Mutation of the $S W I 1$ gene (also known as DYAD) causes a defect in assembly of RAD51 foci on meiotic chromosomes and rescues the chromosome fragmentation phenotype of a recombination-defective difl-1 mutant, strongly indicating that SWI1 is required for initiation of meiotic recombination (Mercier et al. 2003). Two SWII transcripts are produced, capable of encoding proteins of 66 and $73 \mathrm{kDa}$ that differ with respect to presence or absence of $\mathrm{N}$-terminal sequence (Mercier et al. 2001). The proteins contain a potential coiled coil region, but no strong sequence similarity with other proteins has been reported for organisms other than plants (Mercier et al. 2001). The protein is present only very early in meiosis (prior to and during DNA replication) and is chromatin associated (Mercier et al. 2001; Mercier et al. 2003). The swil mutants are sterile and also show alterations in meiotic chromosome behavior not seen with Atspoll mutations, including defects in axial element formation and sister chromatid cohesion (Mercier et al. 2001; Agashe et al. 2002; Mercier et al. 2003). The precise function(s) of this protein and how the different mutant phenotypes are related remain to be determined.

\section{Regulation of DSB Formation}

Recombination initiation is subject to many layers of control that restrict the timing and location of DSBs and that coordinate DSB formation with other aspects of meiotic chromosome dynamics. Although the mechanisms behind these controls are poorly understood, recent studies have provided new insights.

\subsection{Nonrandom Distribution of DSBs Along Chromosomes}

Studies in many organisms demonstrate that meiotic crossovers are more likely to occur in some parts of the genome than in others (reviewed in Petes 2001; de Massy 2003; Kauppi et al. 2004). Because DSBs can be directly mapped in S. cerevisiae, it is known that a primary determinant of the crossover distribution in this organism is the distribution of Spo11dependent DSBs (Wu and Lichten 1994; Baudat and Nicolas 1997; Gerton et al. 2000), although DSB frequencies are much less well correlated with crossover frequencies in $S$. pombe (Young et al. 2002).

DSB distributions in S. cerevisiae display multiple levels of spatial organization. There are hot and cold domains that span large portions of chromosomes (on the order of $100 \mathrm{~kb}$ ) (Zenvirth et al. 1992; Baudat and Nicolas 1997; Gerton et al. 2000). Within these domains, DSBs form in localized hotspots that appear as clusters of frequently cleaved sequences (typically spanning $\sim 70-250$ base pairs) surrounded by sequences in which breaks form rarely, if at all (de Massy et al. 1995; Liu et al. 1995; Xu and Kleckner 1995; Xu and Petes 1996; Baudat and Nicolas 1997). Localized hotspots are a feature of meiotic recombination in S. pombe, mouse, and human as well, but the factors that determine whether a given DNA sequence will be a DSB hotspot are not well understood in any organism. Detailed reviews have been provided elsewhere (Lichten and Goldman 1995; Fox and Smith 1998; Wahls 1998; Petes 2001; de Massy 2003; Kauppi et al. 2004).

Interestingly, Spo11 can be targeted to novel sites in the $S$. cerevisiae genome simply by fusing the protein to a sequence-specific DNA binding domain, such as that of the Gal4 transcription factor (Peciña et al. 2002). Gal4BD-Spo11 still make DSBs at most of the 
normal DSB sites, but more importantly, new DSB sites also appear near Gal4 binding sequences, including sites that lie within larger domains where DSB formation is typically very low (Gerton et al. 2000; Peciña et al. 2002; Robine et al. 2006). DSBs made by Gal4BD-Spo11 still require all of the known DSB proteins (Peciña et al. 2002). However, not all of the binding sites targeted by Gal4BD-Spo11 are capable of giving rise to a DSB, suggesting that targeting of Spo11 to a particular region is not sufficient to recruit all other necessary factors (Robine et al. 2006).

\subsection{Cell Cycle Control}

DSB formation in S. cerevisiae occurs only within a narrow window of time during prophase of the first meiotic division (Padmore et al. 1991). Although the mechanisms that control this timing are not well understood, several features are clear. One is the meiosisspecific accumulation of Spo11 and other proteins required for DSB formation. Another is the direct regulation of DSB formation by CDK-dependent phosphorylation of Mer2 (Smith et al. 2001; Benjamin et al. 2003; Henderson et al. 2006) (see Section 3.1). A third is the coordination of DSB formation with local replication of DNA (see Section 4.3 below). Many features remain to be determined, however. First, it is not known whether CDK influences DSB formation in other ways as well (i.e., independent of Mer2). Second, the regulatory kinase $\mathrm{Cdc} 7$ is also required for DSB formation and thus for recombination (Schild and Byers 1978; Wan et al. 2006). Cdc7 controls DNA replication origin firing in vegetative cells (reviewed by Sclafani 2000; Masai and Arai 2002) and is required for timely and efficient replication in meiosis (Valentin et al. 2006; Wan et al. 2006). The relevant target(s) of Cdc7 kinase activity that are important for meiotic recombination initiation have not yet been reported. Third, even less is understood about the mechanisms that terminate the time when DSBs can form. All of the DSB proteins persist on chromosomes past the time of DSB formation (Kee et al. 2004; Prieler et al. 2005; Li et al. 2006), but how Spo11 is prevented from acting is not known.

DSB timing in $S$. pombe is similarly restricted to a narrow window during prophase I (Cervantes et al. 2000), and at least some of this restriction is likely due to the meiosisspecific expression of Rec12, Rec6, and other factors (Yamamoto et al. 1997; Davis and Smith 2001). Cell cycle regulatory factors have also been implicated in controlling DSB formation. Specifically, gene conversion is reduced $\sim 2-5$-fold in the absence of a meiosisspecific cyclin, Rem1 (although direct measurement of effects on DSB formation have not been reported) (Malapeira et al. 2005). Rem1 is partially redundant with the vegetative Btype cyclin Cig2 for controlling premeiotic DNA replication (Borgne et al. 2002; Malapeira et al. 2005), so it is possible that these cyclins are also redundant for controlling recombination, perhaps analogous to redundancy of Clb5 and Clb6 cyclins in S. cerevisiae (Stuart and Wittenberg 1998; Smith et al. 2001). Moreover, the Hsk1 kinase (the ortholog of Cdc7) is essential for DSB formation, so this means of regulating recombination initiation also appears to be conserved (Ogino et al. 2006). Direct targets of Hsk1 (and possibly of CDK) in DSB formation remain to be determined.

Based on cytological analyses, DSB formation is restricted to early meiotic prophase in other organisms as well. For example, Spol1-dependent $\gamma \mathrm{H} 2 \mathrm{AX}$ appears on mouse spermatocyte chromosomes during the leptotene stage (Mahadevaiah et al. 2001). Detailed timing patterns are not universal, however, as $\gamma$-His2Av formation in Drosophila oocytes does not occur until later in prophase, when SC formation is nearly complete (Jang et al. 2003; Mehrotra and McKim 2006). Regardless of whether DSBs occur relatively early or relatively late, what controls DSB timing in these and other organisms is not yet understood, and in particular whether DSBs are controlled by cell cycle regulatory factors is not known. In this context, however, it is interesting to note that Drosophila MEI-P22 has nine matches 
to the CDK consensus phosphorylation site, so it is tempting to speculate that CDK may directly control MEI-P22 activity.

\subsection{DNA Replication}

In order for meiotic recombination to physically connect homologous chromosomes, recombination must occur between homologous nonsister chromatids, and sister chromatid cohesion along chromosome arms must be maintained until the first meiotic division (Petronczki et al. 2003). This feature of meiotic chromosome biology places an important temporal constraint on DSB formation, namely, that DSBs must occur only in chromosomal segments that have already been replicated. Until recently, it was thought that there is a strict functional dependency in S. cerevisiae whereby DSB formation can only occur after replication fork passage (Borde et al. 2000; Baudat and Keeney 2001; Smith et al. 2001). This view was based in part on observations that recombination initiation is blocked when DNA replication is prevented by mutations (e.g., $c l b 5 / c l b 64, c d c 21$, poll) or chemical inhibitors (e.g., hydroxyurea) (Schild and Byers 1978; Budd et al. 1989; Borde et al. 2000). There are several complications with these studies however. For example, hydroxyurea treatment blocks induction of early meiotic genes, including SPO11 itself (Lamb and Mitchell 2001). Also, CDK is now known to directly regulate DSB formation through phosphorylation of Mer2 (Henderson et al. 2006) in addition to controlling meiotic DNA replication (Stuart and Wittenberg 1998). And checkpoint responses that arrest cell cycle progression are induced by certain mutations that cause replication defects after replication origins have fired (e.g., mutations affecting DNA polymerase $\alpha$ (poll) or thymidylate synthase $(c d c 21)$ ). In principle, activating these checkpoints could cause a regulatory block to DSB formation (Hochwagen and Amon 2006), and indeed this appears to be the case in $S$. pombe because eliminating replication checkpoint genes in this organism permits recombination initiation even when DNA synthesis is inhibited (Tonami et al. 2005; Ogino and Masai 2006). Because of these considerations, the failure of S. cerevisiae cells to make DSBs in these cases cannot be ascribed solely to absence of DNA replication. Finally, when the $S$. cerevisiae replication factor Cdc6 is not expressed in meiotic cells, DSBs are formed even though DNA replication appears not to be initiated (Hochwagen et al. 2005), similar to the previously demonstrated ability of $S$. pombe cells to initiate meiotic recombination when replication factors are depleted (Murakami and Nurse 2001). Thus, in both S. pombe and $S$. cerevisiae, DNA replication is not a strict prerequisite for DSB formation.

Nevertheless, there is strong evidence that DNA replication and DSB formation are closely connected in normal S. cerevisiae cells, from experiments in which replication on the left arm of chromosome III was delayed by deletion of replication origins on that arm or by truncating the arm to bring the telomere close to the sequences normally in the middle of the arm (Borde et al. 2000). In these strains, the delay in replication timing was matched by a corresponding delay in the time of DSB formation by Spo11, such that DSBs always formed $\sim 90$ min after passage of the replication fork. It is possible that replication fork passage promotes establishment of chromosomal features (chromatin or higher order chromosome structures) that constrain subsequent DSB formation (Cha et al. 2000). An alternative possibility is that replication origins and DSB sites compete for a rate-limiting factor(s). If origins compete more effectively and sequester these factors, then DSB sites would not be acted upon until the factors were released locally upon origin firing, or perhaps as the factors track with the replication fork. If pre-replicative complexes never form at origins (e.g., in the absence of Cdc6), then there would be no competition and the rate-limiting factors would be available to activate DSB formation. Cdc28-Clb5/Clb6 and Cdc7-Dbf4 are attractive candidates for such rate-limiting factors (Henderson et al. 2006; Ogino et al. 2006; Wan et al. 2006). 


\subsection{Higher Order Chromosome Structure}

Meiotic chromosomes are organized into linear arrays of chromatin loops, with the loop bases and associated proteins defining a structural axis for each chromatid (reviewed in Kleckner 2006). It appears that meiotic DSBs occur preferentially in the sequences on the loops (Blat et al. 2002), but the recombination complexes that carry out strand exchange and other reactions are associated with the axes (Moens et al. 1998). It has been proposed that protein-DNA complexes at DSB sites are recruited to chromosome axes, either as a condition for DNA cleavage or as a consequence of DSB formation (van Heemst and Heyting 2000; Blat et al. 2002). Supporting this view, DSB formation is partially defective in S. cerevisiae mutants lacking certain chromosome structural components (Red1 and Hop1) (reviewed in Keeney 2001; Hunter 2007). As discussed in Section 3.2, an even more severe DSB defect is seen in S. pombe mutants lacking Rec10 (Lorenz et al. 2004; Wells et al. 2006). The molecular events that connect DSB formation with chromosome axes are not well understood. However, in S. cerevisiae, overexpression of Rec104 can suppress DSB defects caused by hopl mutation, suggesting that the Rec102/Rec104 complex may be involved in this process (Friedman et al. 1994). And in S. pombe, colocalization of Rec7 with linear elements may suggest involvement of this protein (Lorenz et al. 2006).

In Drosophila oocytes, DSB formation appears closely coordinated with formation of the synaptonemal complex: $\gamma$-His2Av appears only after synaptonemal complex is nearly fully formed, and numbers of $\gamma$-His2Av foci are reduced (but not absent) in mutants defective for $\mathrm{C}(3) \mathrm{G}$ and $\mathrm{C}(2) \mathrm{M}$ proteins, which are components of the synaptonemal complex (Jang et al. 2003; Manheim and McKim 2003; Mehrotra and McKim 2006) (but see also Webber et al. 2004). The molecular nature of this dependence remains to be determined. Synaptonemal complex components are not required for DSB formation in other organisms studied, including S. cerevisiae, C. elegans, mouse, and plants (e.g., Sym et al. 1993; Colaiacovo et al. 2003; de Vries et al. 2005; Higgins et al. 2005).

\section{A Model for the Mechanism of DSB Formation in S. cerevisiae}

A working model for steps immediately prior to and just after DSB formation is shown in Figure 6. This model is based on a previous proposal (Keeney 2001), with modifications suggested by more recent studies (especially Neale et al. 2005; Prieler et al. 2005). The first step is the assembly of a Spo11-containing complex on DNA (Figure 6a). This complex likely contains Spo11, Ski8, Rec102, Rec104, and Mre11 and may contain some or all of the other DSB proteins. These complexes are not sufficient to generate a DSB, but must instead be activated (Prieler et al. 2005). In wild-type cells, activation of Spo11-DNA complexes drives them to carry out concerted reactions in which Spo11 cleaves the DNA and Mre11 introduces single-strand nicks (Figure 6b, c), followed rapidly by resection (Figure 6d). This series of steps is envisioned to be the irreversible process that commits this DNA segment to undergoing homologous recombination. It is attractive to propose that DSB formation and processing are concerted reactions because the coupling of these events may provide a means to ensure that DSBs are efficiently repaired.

The biochemical nature of the putative activation step is not clear. One possibility is that there are multiple sub-steps. For example, Spo11 might undergo a conformational change that moves the catalytic tyrosine residues into position to interact with the metal binding pockets (Figure 6b), analogous to conformational changes proposed for TopoVI (see Figure 3) (Nichols et al. 1999; Corbett and Berger 2004). Such a change might poise Spo11 to cleave the DNA in response to other signals (see below), and might be effected by binding of additional DSB proteins, post translational modifications by CDK or other regulatory molecules, and/or ATP-dependent movements by Rad50 or other proteins. Each step up until DNA strand cleavage could in principle be reversible such that only a subset of 
activated complexes actually gives rise to a DSB. Indeed, because Spo11 is in excess over DSB formation, it is reasonable to think that only a few Spo11-DNA complexes are selected to proceed at each step.

If this scheme is correct, what is the ultimate trigger for DSB formation? One hypothesis is that mechanical stress along the chromosome drives this reaction. Kleckner and colleagues have proposed that mechanical stress is generated by expansion of chromatin against constraining elements (Borner et al. 2004; Kleckner et al. 2004; Kleckner 2006). This stress then promotes structural and enzymatic processes on meiotic (and mitotic) chromosomes, including crossover formation. This model could be applied to DSB formation if mechanical stress provides a physical force to favor Spo11 dimer disruption and subsequent activation of Mre11 endonuclease (Keeney 2001) (Figure 6c).

What happens when Mre11 nuclease activity is not available, as in mre11S and (presumably) rad50S and sae2 mutants? Perhaps Spo11 complexes undergo the activation step to establish the potential to make a DSB, stabilizing the complex and giving rise to the "tight binding" observed in ChIP experiments (Prieler et al. 2005). The "tight binding" might reflect stabilization of Spo11 on the DNA by other DSB proteins forming a clamplike higher order structure (Figure 6). However, in the absence of Mre11 nuclease, the complexes cannot carry out concerted Spo11-mediated and Mre11-mediated DNA strand cleavages, so they remain arrested in a quasi-stable state that eventually decays to give an irreversible DSB, perhaps from physical disruption of the Spo11 dimer (Figure 6e). In this scenario, low stress levels are sufficient to drive DSB formation in wild-type cells, but higher stress levels are required to generate irreversible DSBs in rad50S mutants. In this scheme, rad50S DSBs are not on the normal DSB pathway, as has been previously suggested (Prieler et al. 2005).

Application of the stress model to DSB formation is attractive because it provides a way to account for the effects of chromosome structure mutants on DSB formation (section 4.5). This model also explains why DSBs appear to interfere with one another (Wu and Lichten 1995)(M. Lichten, personal communication). This is because the use of stress to drive a reaction results in local relief of the stress. Thus, separate occurrences of the same reaction nearby are inhibited (Kleckner et al. 2004).

This hypothesis is also attractive because it provides an explanation for the evolutionary curiosity of why Spo11 is Spo11, that is to say, why meiotic recombination is initiated by a topoisomerase relative instead of a nuclease. A number of studies have shown that meiotic recombination can be supported by DNA damage mechanisms that do not involve Spo11. For example, DSBs made by site-specific endonucleases induce recombination that has many of the hallmarks of normal meiotic recombination (Malkova et al. 2000; Neale et al. 2002). Moreover, DSBs caused by ionizing radiation can at least partially suppress meiotic inviability of spol1 mutants in many organisms (Thorne and Byers 1993; Dernburg et al. 1998; Celerin et al. 2000; Liu et al. 2002; Storlazzi et al. 2003). Perhaps most strikingly, DNA strand discontinuities caused by elimination of the flap endonuclease $\operatorname{Rad} 2$ in $S$. pombe are sufficient to restore meiotic recombination and spore viability of a rec 12 mutant to near normal levels (Farah et al. 2005a). Why then is Spo11 a universal feature of meiotic recombination even though other mechanisms can substitute? This universality suggests that a topoisomerase-like mechanism is important, not just DNA cleavage per se. I propose that this is because topoisomerases (unlike nucleases, which act hydrolytically) have inherently stress-sensitive catalytic activities: application of mechanical force can in principle drive the cleavage reaction toward irreversibility. Indeed, in single molecule experiments of the decatenation activity of E. coli TopoIV or Drosophila TopoII, application of force to the 
DNA substrate caused the enzymes to stall, attributed to inhibition of the ability to reseal DNA ends (Strick et al. 2000; Stone et al. 2003).

Although there has been significant progress in understanding the mechanism and control of Spo11 activity, much remains to be learned. One challenge that has not yet been met is the development of biochemically tractable systems for studying meiotic recombination initiation. Another challenge is the need to fully catalog Spo11-associated proteins in organisms other than yeasts. The existing studies make it clear, however, that the complexities of meiotic recombination initiation will continue to keep students of this fascinating process busy for many years to come.

\section{Abbreviations}

$\begin{array}{ll}\text { DSB } & \text { DNA double-strand break } \\ \text { CAP } & \text { catabolite activating protein } \\ \text { CDK } & \text { Cyclin-dependent kinase } \\ \text { ChIP } & \text { chromatin immunoprecipitation } \\ \text { MRX } & \text { Mre11-Rad50-Xrs2 complex } \\ \text { TopoVI } & \text { topoisomerase VI }\end{array}$

\section{Acknowledgments}

I thank James Berger, Kevin Corbett, Neil Hunter, and members of the lab for discussions and/or for critical comments on the manuscript, and I thank the many colleagues who communicated information prior to publication. Work from the author's laboratory was funded by US National Institutes of Health grants GM58673 (to S.K.) and HD04196 (to M. Jasin). The author is a Scholar of the Leukemia and Lymphoma Society.

\section{References}

Agashe B, Prasad CK, Siddiqi I. Identification and analysis of $D Y A D$ : a gene required for meiotic chromosome organisation and female meiotic progression in Arabidopsis. Development. 2002; 129:3935-3943. [PubMed: 12135930]

Alani E, Padmore R, Kleckner N. Analysis of wild-type and rad50 mutants of yeast suggests an intimate relationship between meiotic chromosome synapsis and recombination. Cell. 1990; 61:419-436. [PubMed: 2185891]

Araki Y, Takahashi S, Kobayashi T, Kajiho H, Hoshino S, Katada T. Ski7p G protein interacts with the exosome and the Ski complex for 3'-to-5' mRNA decay in yeast. EMBO J. 2001; 20:4684-4693. [PubMed: 11532933]

Aravind L, Leipe DD, Koonin EV. Toprim-A conserved catalytic domain in type IA and II topoisomerases, DnaG-type primases, OLD family nucleases and RecR proteins. Nucl Acids Res. 1998; 26:4205-4213. [PubMed: 9722641]

Arora C, Kee K, Maleki S, Keeney S. Antiviral protein Ski8 is a direct partner of Spo11 in meiotic DNA break formation, independent of its cytoplasmic role in RNA metabolism. Mol Cell. 2004; 13:549-559. [PubMed: 14992724]

Assenmacher N, Hopfner KP. MRE11/RAD50/NBS1: complex activities. Chromosoma. 2004; 113:157-166. [PubMed: 15309560]

Atcheson CL, DiDomenico B, Frackman S, Esposito RE, Elder RT. Isolation, DNA sequence, and regulation of a meiosis-specific eukaryotic recombination gene. Proc Natl Acad Sci USA. 1987; 84:8035-8039. [PubMed: 3317399]

Baudat F, Nicolas A. Clustering of meiotic double-strand breaks on yeast Chromosome III. Proc Natl Acad Sci USA. 1997; 94:5213-5218. [PubMed: 9144217] 
Baudat F, Manova K, Yuen JP, Jasin M, Keeney S. Chromosome synapsis defects and sexually dimorphic meiotic progression in mice lacking Spo11. Mol Cell. 2000; 6:989-998. [PubMed: 11106739]

Baudat F, Keeney S. Meiotic recombination: Making and breaking go hand in hand. Curr Biol. 2001; 11:R45-R48. [PubMed: 11231139]

Becker E, Meyer V, Madaoui H, Guerois R. Detection of a tandem BRCT in Nbs1 and Xrs2 with functional implications in the DNA damage response. Bioinformatics. 2006; 22:1289-1292. [PubMed: 16522671]

Bender CF, et al. Cancer predisposition and hematopoietic failure in $\operatorname{Rad} 50^{S / S}$ mice. Genes Dev. 2002; 16:2237-2251. [PubMed: 12208847]

Benjamin KR, Zhang C, Shokat KM, Herskowitz I. Control of landmark events in meiosis by the CDK Cdc28 and the meiosis-specific kinase Ime2. Genes Dev. 2003; 17:1524-1539. [PubMed: 12783856]

Berger JM, Fass D, Wang JC, Harrison SC. Structural similarities between topoisomerases that cleave one or both DNA strands. Proc Natl Acad Sci USA. 1998; 95:7876-7881. [PubMed: 9653108]

Bergerat A, de Massy B, Gadelle D, Varoutas PC, Nicolas A, Forterre P. An atypical topoisomerase II from Archaea with implications for meiotic recombination. Nature. 1997; 386:414-417. [PubMed: 9121560]

Bishop DK, Park D, Xu L, Kleckner N. DMC1: a meiosis-specific yeast homolog of E. coli recA required for recombination, synaptonemal complex formation, and cell cycle progression. Cell. 1992; 69:439-456. [PubMed: 1581960]

Bishop DK, Nikolski Y, Oshiro J, Chon J, Shinohara M, Chen X. High copy number suppression of the meiotic arrest caused by a dmcl mutation: REC114 imposes an early recombination block and $R A D 54$ promotes a DMC1-independent DSB repair pathway. Genes Cells. 1999; 4:425-444. [PubMed: 10526232]

Bishop DK, Zickler D. Early decision; meiotic crossover interference prior to stable strand exchange and synapsis. Cell. 2004; 117:9-15. [PubMed: 15066278]

Blat Y, Protacio RU, Hunter N, Kleckner N. Physical and functional interactions among basic chromosome organizational features govern early steps of meiotic chiasma formation. Cell. 2002; 111:791-802. [PubMed: 12526806]

Bleuyard JY, Gallego ME, White CI. Meiotic defects in the Arabidopsis rad50 mutant point to conservation of the MRX complex function in early stages of meiotic recombination. Chromosoma. 2004; 113:197-203. [PubMed: 15309561]

Borde V, Goldman ASH, Lichten M. Direct coupling between meiotic DNA replication and recombination initiation. Science. 2000; 290:806-809. [PubMed: 11052944]

Borde V, Lin W, Novikov E, Petrini JH, Lichten M, Nicolas A. Association of Mre11p with doublestrand break sites during yeast meiosis. Mol Cell. 2004; 13:389-401. [PubMed: 14967146]

Borgne A, Murakami H, Ayte J, Nurse P. The G1/S cyclin Cig2p during meiosis in fission yeast. Mol Biol Cell. 2002; 13:2080-2090. [PubMed: 12058071]

Borner GV, Kleckner N, Hunter N. Crossover/noncrossover differentiation, synaptonemal complex formation, and regulatory surveillance at the leptotene/zygotene transition of meiosis. Cell. 2004; 117:29-45. [PubMed: 15066280]

Bowring FJ, Yeadon PJ, Stainer RG, Catcheside DE. Chromosome pairing and meiotic recombination in Neurospora crassa spo11 mutants. Curr Genet. 2006; 50:115-123. [PubMed: 16758206]

Brown JT, Bai X, Johnson AW. The yeast antiviral proteins Ski2p, Ski3p, and Ski8p exist as a complex in vivo. RNA. 2000; 6:449-457. [PubMed: 10744028]

Budd ME, Wittrup KD, Bailey JE, Campbell JL. DNA polymerase I is required for premeiotic DNA replication and sporulation but not for X-ray repair in Saccharomyces cerevisiae. Mol Cell Biol. 1989; 9:365-376. [PubMed: 2651896]

Buhler C, Gadelle D, Forterre P, Wang JC, Bergerat A. Reconstitution of DNA topoisomerase VI of the thermophilic archaeon Sulfolobus shibatae from subunits separately overexpressed in Escherichia coli. Nucl Acids Res. 1998; 26:5157-5162. [PubMed: 9801313] 
Buhler C, Lebbink JH, Bocs C, Ladenstein R, Forterre P. DNA topoisomerase VI generates ATPdependent double-strand breaks with two-nucleotide overhangs. J Biol Chem. 2001; 276:3721537222. [PubMed: 11485995]

Celerin M, Merino ST, Stone JE, Menzie AM, Zolan ME. Multiple roles of Spo11 in meiotic chromosome behavior. EMBO J. 2000; 19:2739-2750. [PubMed: 10835371]

Cervantes MD, Farah JA, Smith GR. Meiotic DNA breaks associated with recombination in S. pombe. Mol Cell. 2000; 5:883-888. [PubMed: 10882124]

Cha RS, Weiner BM, Keeney S, Dekker J, Kleckner N. Progression of meiotic DNA replication is modulated by interchromosomal interaction proteins, negatively by Spo11p and positively by Rec8p. Genes Dev. 2000; 14:493-503. [PubMed: 10691741]

Chahwan C, Nakamura TM, Sivakumar S, Russell P, Rhind N. The fission yeast Rad32 (Mre11)Rad50-Nbs1 complex is required for the S-phase DNA damage checkpoint. Mol Cell Biol. 2003; 23:6564-6573. [PubMed: 12944482]

Champoux JJ. DNA topoisomerases: structure, function, and mechanism. Annu Rev Biochem. 2001; 70:369-413. [PubMed: 11395412]

Cheng Z, Liu Y, Wang C, Parker R, Song H. Crystal structure of Ski8p, a WD-repeat protein with dual roles in mRNA metabolism and meiotic recombination. Protein Sci. 2004; 13:2673-2684. [PubMed: 15340168]

Chin GM, Villeneuve AM. C. elegans mre-11 is required for meiotic recombination and DNA repair but is dispensable for the meiotic G(2) DNA damage checkpoint. Genes Dev. 2001; 15:522-534. [PubMed: 11238374]

Chu S, Herskowitz I. Gametogenesis in yeast is regulated by a transcriptional cascade dependent on Ndt80. Mol Cell. 1998; 1:685-696. [PubMed: 9660952]

Cliften PF, et al. Surveying Saccharomyces genomes to identify functional elements by comparative DNA sequence analysis. Genome Res. 2001; 11:1175-1186. [PubMed: 11435399]

Clouaire T, Roussigne M, Ecochard V, Mathe C, Amalric F, Girard JP. The THAP domain of THAP1 is a large $\mathrm{C} 2 \mathrm{CH}$ module with zinc-dependent sequence-specific DNA-binding activity. Proc Natl Acad Sci USA. 2005; 102:6907-6912. [PubMed: 15863623]

Colaiacovo MP, et al. Synaptonemal complex assembly in C. elegans Is dispensable for loading strand-exchange proteins but critical for proper completion of recombination. Dev Cell. 2003; 5:463-474. [PubMed: 12967565]

Cooper KF, Mallory MJ, Egeland DB, Jarnik M, Strich R. Ama1p is a meiosis-specific regulator of the anaphase promoting complex/cyclosome in yeast. Proc Natl Acad Sci USA. 2000; 97:1454814553. [PubMed: 11114178]

Corbett KD, Berger JM. Structure of the topoisomerase VI-B subunit: implications for type II topoisomerase mechanism and evolution. EMBO J. 2003; 22:151-163. [PubMed: 12505993]

Corbett KD, Berger JM. Structure, molecular mechanisms, and evolutionary relationships in DNA topoisomerases. Annu Rev Biophys Biomol Struct. 2004; 33:95-118. [PubMed: 15139806]

Corbett KD, Berger JM. Structural dissection of ATP turnover in the prototypical GHL ATPase TopoVI. Structure. 2005; 13:873-882. [PubMed: 15939019]

Davis CA, Grate L, Spingola M, Ares M Jr. Test of intron predictions reveals novel splice sites, alternatively spliced mRNAs and new introns in meiotically regulated genes of yeast. Nucl Acids Res. 2000; 28:1700-1706. [PubMed: 10734188]

Davis L, Smith GR. Meiotic recombination and chromosome segregation in Schizosaccharomyces pombe. Proc Natl Acad Sci USA. 2001; 98:8395-8402. [PubMed: 11459981]

de Massy B, Rocco V, Nicolas A. The nucleotide mapping of DNA double-strand breaks at the CYS3 initiation site of meiotic recombination in Saccharomyces cerevisiae. EMBO J. 1995; 14:45894598. [PubMed: 7556102]

de Massy B. Distribution of meiotic recombination sites. Trends Genet. 2003; 19:514-522. [PubMed: 12957545]

De Veaux LC, Hoagland NA, Smith GR. Seventeen complementation groups of mutations decreasing meiotic recombination in Schizosaccharomyces pombe. Genetics. 1992; 130:251-262. [PubMed: 1541389] 
de Vries FA, et al. Mouse Sycpl functions in synaptonemal complex assembly, meiotic recombination, and XY body formation. Genes Dev. 2005; 19:1376-1389. [PubMed: 15937223]

Dernburg AF, McDonald K, Moulder G, Barstead R, Dresser M, Villeneuve AM. Meiotic recombination in C. elegans initiates by a conserved mechanism and is dispensable for homologous chromosome synapsis. Cell. 1998; 94:387-398. [PubMed: 9708740]

DeVeaux LC, Smith GR. Region-specific activators of meiotic recombination in Schizosaccharomyces pombe. Genes Dev. 1994; 8:203-210. [PubMed: 8299939]

DeWall KM, Davidson MK, Sharif WD, Wiley CA, Wahls WP. A DNA binding motif of meiotic recombinase Rec12 (Spo11) defined by essential glycine-202, and persistence of Rec12 protein after completion of recombination. Gene. 2005; 356:77-84. [PubMed: 16009511]

Diaz RL, Alcid AD, Berger JM, Keeney S. Identification of residues in yeast Spo11p critical for meiotic DNA double-strand break formation. Mol Cell Biol. 2002; 22:1106-1115. [PubMed: 11809802]

Doll E, Molnar M, Hiraoka Y, Kohli J. Characterization of rec15, an early meiotic recombination gene in Schizosaccharomyces pombe. Curr Genet. 2005; 48:323-333. [PubMed: 16252089]

Dresser ME, et al. DMC1 functions in a Saccharomyces cerevisiae meiotic pathway that is largely independent of the RAD51 pathway. Genetics. 1997; 147:533-544. [PubMed: 9335591]

Durocher D, Jackson SP. The FHA domain. FEBS Lett. 2002; 513:58-66. [PubMed: 11911881]

Dutta R, Inouye M. GHKL, an emergent ATPase/kinase superfamily. Trends Biochem Sci. 2000; 25:24-28. [PubMed: 10637609]

Ellermeier C, Smith GR. Cohesins are required for meiotic DNA breakage and recombination in Schizosaccharomyces pombe. Proc Natl Acad Sci USA. 2005; 102:10952-10957. [PubMed: 16043696]

Engebrecht JA, Voelkel-Meiman K, Roeder GS. Meiosis-specific RNA splicing in yeast. Cell. 1991; 66:1257-1268. [PubMed: 1840507]

Evans DH, Li YF, Fox ME, Smith GR. A WD repeat protein, Rec14, essential for meiotic recombination in Schizosaccharomyces pombe. Genetics. 1997; 146:1253-1264. [PubMed: 9258671]

Farah JA, Hartsuiker E, Mizuno K, Ohta K, Smith GR. A 160-bp palindrome is a Rad50.Rad32dependent mitotic recombination hotspot in Schizosaccharomyces pombe. Genetics. 2002; 161:461-468. [PubMed: 12019258]

Farah JA, Cromie G, Davis L, Steiner WW, Smith GR. Activation of an alternative, rec12 (spol1)independent pathway of fission yeast meiotic recombination in the absence of a DNA flap endonuclease. Genetics. 2005a; 171:1499-1511. [PubMed: 16118186]

Farah JA, Cromie G, Steiner WW, Smith GR. A novel recombination pathway initiated by the Mre11/ Rad50/Nbs1 complex eliminates palindromes during meiosis in Schizosaccharomyces pombe. Genetics. 2005b; 169:1261-1274. [PubMed: 15654094]

Fernandez-Capetillo O, Lee A, Nussenzweig M, Nussenzweig A. H2AX: the histone guardian of the genome. DNA Repair (Amst). 2004; 3:959-967. [PubMed: 15279782]

Fox ME, Smith GR. Control of meiotic recombination in Schizosaccharomyces pombe. Prog Nucleic Acid Res Mol Biol. 1998; 61:345-378. [PubMed: 9752725]

Friedman DB, Hollingsworth NM, Byers B. Insertional mutations in the yeast $H O P 1$ gene: evidence for multimeric assembly in meiosis. Genetics. 1994; 136:449-464. [PubMed: 8150275]

Furuse M, Nagase Y, Tsubouchi H, Murakami-Murofushi K, Shibata T, Ohta K. Distinct roles of two separable in vitro activities of yeast Mre11 in mitotic and meiotic recombination. EMBO J. 1998; 17:6412-6425. [PubMed: 9799249]

Gadelle D, Filee J, Buhler C, Forterre P. Phylogenomics of type II DNA topoisomerases. Bioessays. 2003; 25:232-242. [PubMed: 12596227]

Gardiner JM, Bullard SA, Chrome C, Malone RE. Molecular and genetic analysis of REC103, an early meiotic recombination gene in yeast. Genetics. 1997; 146:1265-1274. [PubMed: 9258672]

Gerecke EE, Zolan ME. An mre11 mutant of Coprinus cinereus has defects in meiotic chromosome pairing, condensation and synapsis. Genetics. 2000; 154:1125-1139. [PubMed: 10757758] 
Gerton JL, DeRisi J, Shroff R, Lichten M, Brown PO, Petes TD. Inaugural article: global mapping of meiotic recombination hotspots and coldspots in the yeast Saccharomyces cerevisiae. Proc Natl Acad Sci USA. 2000; 97:11383-11390. [PubMed: 11027339]

Glover JN, Williams RS, Lee MS. Interactions between BRCT repeats and phosphoproteins: tangled up in two. Trends Biochem Sci. 2004; 29:579-585. [PubMed: 15501676]

Gregan J, et al. Novel genes required for meiotic chromosome segregation are identified by a highthroughput knockout screen in fission yeast. Curr Biol. 2005; 15:1663-1669. [PubMed: 16169489]

Grelon M, Vezon D, Gendrot G, Pelletier G. AtSPO11-1 is necessary for efficient meiotic recombination in plants. EMBO J. 2001; 20:589-600. [PubMed: 11157765]

Grelon M, Gendrot G, Vezon D, Pelletier G. The Arabidopsis MEIl gene encodes a protein with five BRCT domains that is involved in meiosis-specific DNA repair events independent of SPO11induced DSBs. Plant J. 2003; 35:465-475. [PubMed: 12904209]

Hartung F, Puchta H. Molecular characterisation of two paralogous SPO11 homologues in Arabidopsis thaliana. Nucl Acids Res. 2000; 28:1548-1554. [PubMed: 10710421]

Hartung F, Puchta H. Molecular characterization of homologues of both subunits A (SPO11) and B of the archaebacterial topoisomerase 6 in plants. Gene. 2001; 271:81-86. [PubMed: 11410368]

Hartung F, Angelis KJ, Meister A, Schubert I, Melzer M, Puchta H. An archaebacterial topoisomerase homolog not present in other eukaryotes is indispensable for cell proliferation of plants. Curr Biol. 2002; 12:1787-1791. [PubMed: 12401176]

He F, Li X, Spatrick P, Casillo R, Dong S, Jacobson A. Genome-wide analysis of mRNAs regulated by the nonsense-mediated and 5' to 3' mRNA decay pathways in yeast. Mol Cell. 2003; 12:14391452. [PubMed: 14690598]

Henderson KA, Kee K, Maleki S, Santini PA, Keeney S. Cyclin-dependent kinase directly regulates initiation of meiotic recombination. Cell. 2006; 125:1321-1332. [PubMed: 16814718]

Higgins JD, Sanchez-Moran E, Armstrong SJ, Jones GH, Franklin FC. The Arabidopsis synaptonemal complex protein ZYP1 is required for chromosome synapsis and normal fidelity of crossing over. Genes Dev. 2005; 19:2488-2500. [PubMed: 16230536]

Hochwagen A, Tham WH, Brar GA, Amon A. The FK506 binding protein Fpr3 counteracts protein phosphatase 1 to maintain meiotic recombination checkpoint activity. Cell. 2005; 122:861-873. [PubMed: 16179256]

Hochwagen A, Amon A. Checking your breaks: surveillance mechanisms of meiotic recombination. Curr Biol. 2006; 16:R217-R228. [PubMed: 16546077]

Hopfner KP, et al. The Rad50 zinc-hook is a structure joining Mre11 complexes in DNA recombination and repair. Nature. 2002; 418:562-566. [PubMed: 12152085]

Hopfner, KP. Structure and function of Rad50/SMC protein complexes in chromosome biology. In: Lankenau, DH., editor. Genome Integrity: Facets and Perspectives. Vol. vol 1. Springer; 2006.

Hunter, N. Meiotic recombination. In: Aguilera, A.; Rothstein, R., editors. Recombination. Springer; 2007. $p$ in press

Jacobs Anderson JS, Parker R. The 3' to 5' degradation of yeast mRNAs is a general mechanism for mRNA turnover that requires the SKI2 DEVH box protein and $3^{\prime}$ to $5^{\prime}$ exonucleases of the exosome complex. EMBO J. 1998; 17:1497-1506. [PubMed: 9482746]

Jang JK, Sherizen DE, Bhagat R, Manheim EA, McKim KS. Relationship of DNA double-strand breaks to synapsis in Drosophila. J Cell Sci. 2003; 116:3069-3077. [PubMed: 12799415]

Jiao K, Salem L, Malone R. Support for a meiotic recombination initiation complex: interactions among Rec102p, Rec104p, and Spo11p. Mol Cell Biol. 2003; 23:5928-5938. [PubMed: 12897161]

Jolivet S, Vezon D, Froger N, Mercier R. Non conservation of the meiotic function of the Ski8/Rec103 homolog in Arabidopsis. Genes Cells. 2006; 11:615-622. [PubMed: 16716192]

Juneau K, Palm C, Miranda M, Davis RW. High-density yeast-tiling array reveals previously undiscovered introns and extensive regulation of meiotic splicing. Proc Natl Acad Sci USA. 2007; 104:1522-1527. [PubMed: 17244705]

Kauppi L, Jeffreys AJ, Keeney S. Where the crossovers are: recombination distributions in mammals. Nat Rev Genet. 2004; 5:413-424. [PubMed: 15153994] 
Kee K, Keeney S. Functional interactions between SPO11 and REC102 during initiation of meiotic recombination in Saccharomyces cerevisiae. Genetics. 2002; 160:111-122. [PubMed: 11805049]

Kee K, Protacio RU, Arora C, Keeney S. Spatial organization and dynamics of the association of Rec102 and Rec104 with meiotic chromosomes. EMBO J. 2004; 23:1815-1824. [PubMed: 15044957]

Keeney S, Kleckner N. Covalent protein-DNA complexes at the 5' strand termini of meiosis-specific double-strand breaks in yeast. Proc Natl Acad Sci USA. 1995; 92:11274-11278. [PubMed: 7479978]

Keeney S, Giroux CN, Kleckner N. Meiosis-specific DNA double-strand breaks are catalyzed by Spo11, a member of a widely conserved protein family. Cell. 1997; 88:375-384. [PubMed: 9039264]

Keeney S. Mechanism and control of meiotic recombination initiation. Curr Top Dev Biol. 2001; 52:1-53. [PubMed: 11529427]

Kitajima TS, Yokobayashi S, Yamamoto M, Watanabe Y. Distinct cohesin complexes organize meiotic chromosome domains. Science. 2003; 300:1152-1155. [PubMed: 12750522]

Kleckner N, et al. A mechanical basis for chromosome function. Proc Natl Acad Sci USA. 2004; 101:12592-12597. [PubMed: 15299144]

Kleckner N. Chiasma formation: chromatin/axis interplay and the role(s) of the synaptonemal complex. Chromosoma. 2006; 115:175-194. [PubMed: 16555016]

Klein F, et al. A central role for cohesins in sister chromatid cohesion, formation of axial elements, and recombination during yeast meiosis. Cell. 1999; 98:91-103. [PubMed: 10412984]

Klein U, Esposito G, Baudat F, Keeney S, Jasin M. Mice deficient for the type II topoisomerase-like DNA transesterase Spo11 show normal immunoglobulin somatic hypermutation and class switching. Eur J Immunol. 2002; 32:316-321. [PubMed: 11807770]

Krawchuk MD, DeVeaux LC, Wahls WP. Meiotic chromosome dynamics dependent upon the $r e c 8^{+}$, recl $\mathrm{O}^{+}$and $\mathrm{recll}^{+}$genes of the fission yeast Schizosaccharomyces pombe. Genetics. 1999; 153:57-68. [PubMed: 10471700]

Krogh BO, Symington LS. Recombination proteins in yeast. Annu Rev Genet. 2004; 38:233-271. [PubMed: 15568977]

Lamb TM, Mitchell AP. Coupling of Saccharomyces cerevisiae early meiotic gene expression to DNA replication depends upon RPD3 and SIN3. Genetics. 2001; 157:545-556. [PubMed: 11156977]

Lankenau, DH. Germline double-strand break repair and gene targeting in Drosophila: A trajectory system throughout evolution. In: Egel, R.; Lankenau, DH., editors. Genome Dynamics and Stability. Vol. vol 1. Berlin Heidelberg: Springer-Verlag; 2006.

Li J, Hooker GW, Roeder GS. Saccharomyces cerevisiae Mer2, Mei4 and Rec114 form a complex required for meiotic double-strand break formation. Genetics. 2006; 173:1969-1981. [PubMed: 16783010]

Libby BJ, et al. The mouse meiotic mutation meil disrupts chromosome synapsis with sexually dimorphic consequences for meiotic progression. Dev Biol. 2002; 242:174-187. [PubMed: 11820814]

Libby BJ, Reinholdt LG, Schimenti JC. Positional cloning and characterization of Meil, a vertebratespecific gene required for normal meiotic chromosome synapsis in mice. Proc Natl Acad Sci USA. 2003; 100:15706-15711. [PubMed: 14668445]

Lichten M, Goldman AS. Meiotic recombination hotspots. Annu Rev Genet. 1995; 29:423-444. [PubMed: 8825482]

Lin Y, Larson KL, Dorer R, Smith GR. Meiotically induced rec7 and rec8 genes of Schizosaccharomyces pombe. Genetics. 1992; 132:75-85. [PubMed: 1339382]

Lin Y, Smith GR. Transient, meiosis-induced expression of the rec6 and rec12 genes of Schizosaccharomyces pombe. Genetics. 1994; 136:769-779. [PubMed: 8005432]

Lin Y, Smith GR. An intron-containing meiosis-induced recombination gene, rec15, of Schizosaccharomyces pombe. Mol Microbiol. 1995; 17:439-448. [PubMed: 8559063]

Liu H, Jang JK, Kato N, McKim KS. mei-P22 encodes a chromosome-associated protein required for the initiation of meiotic recombination in Drosophila melanogaster. Genetics. 2002; 162:245258. [PubMed: 12242237] 
Liu J, Wu T-C, Lichten M. The location and structure of double-strand DNA breaks induced during yeast meiosis: evidence for a covalently linked DNA-protein intermediate. EMBO J. 1995; 14:4599-4608. [PubMed: 7556103]

Loidl J. S. pombe linear elements: the modest cousins of synaptonemal complexes. Chromosoma. 2006; 115:260-271. [PubMed: 16532354]

Lorenz A, et al. S. pombe meiotic linear elements contain proteins related to synaptonemal complex components. J Cell Sci. 2004; 117:3343-3351. [PubMed: 15226405]

Lorenz A, Estreicher A, Kohli J, Loidl J. Meiotic recombination proteins localize to linear elements in Schizosaccharomyces pombe. Chromosoma. 2006; 115:330-340. [PubMed: 16532353]

Luo G, et al. Disruption of $m$ Rad50 causes embryonic stem cell lethality, abnormal embryonic development, and sensitivity to ionizing radiation. Proc Natl Acad Sci USA. 1999; 96:73767381. [PubMed: 10377422]

Madrona AY, Wilson DK. The structure of Ski8p, a protein regulating mRNA degradation: Implications for WD protein structure. Protein Sci. 2004; 13:1557-1565. [PubMed: 15152089]

Mahadevaiah SK, et al. Recombinational DNA double strand breaks in mice precede synapsis. Nat Genet. 2001; 27:271-276. [PubMed: 11242108]

Malapeira J, Moldon A, Hidalgo E, Smith GR, Nurse P, Ayte J. A meiosis-specific cyclin regulated by splicing is required for proper progression through meiosis. Mol Cell Biol. 2005; 25:6330-6337. [PubMed: 16024772]

Malkova A, Klein F, Leung WY, Haber JE. HO endonuclease-induced recombination in yeast meiosis resembles Spo11- induced events. Proc Natl Acad Sci USA. 2000; 97:14500-14505. [PubMed: 11121053]

Malone RE, Pittman DL, Nau JJ. Examination of the intron in the meiosis-specific recombination gene REC114 in Saccharomyces. Mol Gen Genet. 1997; 255:410-419. [PubMed: 9267437]

Manheim EA, McKim KS. The synaptonemal complex component C(2)M regulates meiotic crossing over in Drosophila. Curr Biol. 2003; 13:276-285. [PubMed: 12593793]

Martin-Castellanos C, et al. A large-scale screen in $S$. pombe identifies seven novel genes required for critical meiotic events. Curr Biol. 2005; 15:2056-2062. [PubMed: 16303567]

Masai H, Arai K. Cdc7 kinase complex: a key regulator in the initiation of DNA replication. J Cell Physiol. 2002; 190:287-296. [PubMed: 11857444]

Masison DC, Blanc A, Ribas JC, Carroll K, Sonenberg N, Wickner RB. Decoying the cap ${ }^{-}$mRNA degradation system by a double-stranded RNA virus and poly(A)- mRNA surveillance by a yeast antiviral system. Mol Cell Biol. 1995; 15:2763-2771. [PubMed: 7739557]

Mazina OM, Mazin AV, Nakagawa T, Kolodner RD, Kowalczykowski SC. Saccharomyces cerevisiae Mer3 helicase stimulates 3'-5' heteroduplex extension by Rad51; implications for crossover control in meiotic recombination. Cell. 2004; 117:47-56. [PubMed: 15066281]

McKee AH, Kleckner N. A general method for identifying recessive diploid-specific mutations in Saccharomyces cerevisiae, its application to the isolation of mutants blocked at intermediate stages of meiotic prophase and characterization of a new gene SAE2. Genetics. 1997; 146:797816. [PubMed: 9215888]

McKee BD. Pairing sites and the role of chromosome pairing in meiosis and spermatogenesis in male Drosophila. Curr Top Dev Biol. 1998; 37:77-115. [PubMed: 9352184]

McKim KS, et al. Meiotic synapsis in the absence of recombination. Science. 1998; 279:876-878. [PubMed: 9452390]

McKim KS, Hayashi-Hagihara A. mei-W68 in Drosophila melanogaster encodes a Spo11 homolog: evidence that the mechanism for initiating meiotic recombination is conserved. Genes Dev. 1998; 12:2932-2942. [PubMed: 9744869]

Mehrotra S, McKim KS. Temporal analysis of meiotic DNA double-strand break formation and repair in Drosophila females. PLoS Genet. 2006; 2:e200. [PubMed: 17166055]

Mercier R, et al. SWITCH1 (SWI1): a novel protein required for the establishment of sister chromatid cohesion and for bivalent formation at meiosis. Genes Dev. 2001; 15:1859-1871. [PubMed: 11459834]

Mercier R, et al. The meiotic protein SWI1 is required for axial element formation and recombination initiation in Arabidopsis. Development. 2003; 130:3309-3318. [PubMed: 12783800] 
Merino ST, Cummings WJ, Acharya SN, Zolan ME. Replication-dependent early meiotic requirement for Spo11 and Rad50. Proc Natl Acad Sci USA. 2000; 97:10477-10482. [PubMed: 10973500]

Moens PB, Pearlman RE, Heng HH, Traut W. Chromosome cores and chromatin at meiotic prophase. Curr Top Dev Biol. 1998; 37:241-262. [PubMed: 9352188]

Molnar M, Bahler J, Sipiczki M, Kohli J. The rec8 gene of Schizosaccharomyces pombe is involved in linear element formation, chromosome pairing and sister-chromatid cohesion during meiosis. Genetics. 1995; 141:61-73. [PubMed: 8536990]

Molnar M, et al. Characterization of $r e c 7$, an early meiotic recombination gene in Schizosaccharomyces pombe. Genetics. 2001; 157:519-532. [PubMed: 11156975]

Molnar M, Doll E, Yamamoto A, Hiraoka Y, Kohli J. Linear element formation and their role in meiotic sister chromatid cohesion and chromosome pairing. J Cell Sci. 2003; 116:1719-1731. [PubMed: 12665553]

Morales M, Theunissen JW, Kim CF, Kitagawa R, Kastan MB, Petrini JH. The Rad50S allele promotes ATM-dependent DNA damage responses and suppresses ATM deficiency: implications for the Mre11 complex as a DNA damage sensor. Genes Dev. 2005; 19:3043-3054. [PubMed: 16357220]

Moreau S, Ferguson JR, Symington LS. The nuclease activity of Mre11 is required for meiosis but not for mating type switching, end joining, or telomere maintenance. Mol Cell Biol. 1999; 19:556566. [PubMed: 9858579]

Murakami H, Nurse P. Regulation of premeiotic S phase and recombination-related double-strand DNA breaks during meiosis in fission yeast. Nat Genet. 2001; 28:290-293. [PubMed: 11431703]

Nag DK, Pata JD, Sironi M, Flood DR, Hart AM. Both conserved and non-conserved regions of Spo11 are essential for meiotic recombination initiation in yeast. Mol Genet Genomics. 2006; 276:313321. [PubMed: 16816949]

Nakagawa T, Ogawa H. Involvement of the MRE2 gene of yeast in formation of meiosis-specific double-strand breaks and crossover recombination through RNA splicing. Genes Cells. 1997; 2:65-79. [PubMed: 9112441]

Nakagawa T, Ogawa H. The Saccharomyces cerevisiae MER3 gene, encoding a novel helicase-like protein, is required for crossover control in meiosis. EMBO J. 1999; 18:5714-5723. [PubMed: 10523314]

Nandabalan K, Price L, Roeder GS. Mutations in U1 snRNA bypass the requirement for a cell typespecific RNA splicing factor. Cell. 1993; 73:407-415. [PubMed: 8477451]

Nandabalan K, Roeder GS. Binding of a cell-type-specific RNA splicing factor to its target regulatory sequence. Mol Cell Biol. 1995; 15:1953-1960. [PubMed: 7891689]

Neale MJ, Ramachandran M, Trelles-Sticken E, Scherthan H, Goldman ASH. In Saccharomyces cerevisiae, wild-type levels of Spo11-induced double-strand breaks are required for normal regulation of single-strand resection during meiosis. Mol Cell. 2002; 9:835-846. [PubMed: 11983174]

Neale MJ, Pan J, Keeney S. Endonucleolytic processing of covalent protein-linked DNA double-strand breaks. Nature. 2005; 436:1053-1057. [PubMed: 16107854]

Nichols MD, DeAngelis K, Keck JL, Berger JM. Structure and function of an archaeal topoisomerase VI subunit with homology to the meiotic recombination factor Spo11. EMBO J. 1999; 18:61776188. [PubMed: 10545127]

Ogino K, et al. Hsk1 kinase is required for induction of meiotic dsDNA breaks without involving checkpoint kinases in fission yeast. Proc Natl Acad Sci USA. 2006; 103:8131-8136. [PubMed: 16698922]

Ogino K, Masai H. Rad3-Cds1 mediates coupling of initiation of meiotic recombination with DNA replication. Mei4-dependent transcription as a potential target of meiotic checkpoint. J Biol Chem. 2006; 281:1338-1344. [PubMed: 16286472]

Padmore R, Cao L, Kleckner N. Temporal comparison of recombination and synaptonemal complex formation during meiosis in S. cerevisiae. Cell. 1991; 66:1239-1256. [PubMed: 1913808]

Page SL, Hawley RS. Chromosome choreography: the meiotic ballet. Science. 2003; 301:785-789. [PubMed: 12907787] 
Paques F, Haber JE. Multiple pathways of recombination induced by double-strand breaks in Saccharomyces cerevisiae. Microbiol Mol Biol Rev. 1999; 63:349-404. [PubMed: 10357855]

Parisi S, et al. Rec8p, a meiotic recombination and sister chromatid cohesion phosphoprotein of the Rad21p family conserved from fission yeast to humans. Mol Cell Biol. 1999; 19:3515-3528. [PubMed: 10207075]

Peciña A, Smith KN, Mezard C, Murakami H, Ohta K, Nicolas A. Targeted stimulation of meiotic recombination. Cell. 2002; 111:173-184. [PubMed: 12408862]

Petes TD. Meiotic recombination hot spots and cold spots. Nat Rev Genet. 2001; 2:360-369. [PubMed: 11331902]

Petronczki M, Siomos MF, Nasmyth K. Un menage a quatre: the molecular biology of chromosome segregation in meiosis. Cell. 2003; 112:423-440. [PubMed: 12600308]

Ponticelli AS, Smith GR. Meiotic recombination-deficient mutants of Schizosaccharomyces pombe. Genetics. 1989; 123:45-54. [PubMed: 2806887]

Prieler S, Penkner A, Borde V, Klein F. The control of Spo11's interaction with meiotic recombination hotspots. Genes Dev. 2005; 19:255-269. [PubMed: 15655113]

Prinz S, Amon A, Klein F. Isolation of COM1, a new gene required to complete meiotic double-strand break-induced recombination in Saccharomyces cerevisiae. Genetics. 1997; 146:781-795. [PubMed: 9215887]

Puizina J, Siroky J, Mokros P, Schweizer D, Riha K. Mre11 deficiency in Arabidopsis is associated with chromosomal instability in somatic cells and Spo11-dependent genome fragmentation during meiosis. Plant Cell. 2004; 16:1968-1978. [PubMed: 15258261]

Qin J, Richardson LL, Jasin M, Handel MA, Arnheim N. Mouse strains with an active H2-Ea meiotic recombination hot spot exhibit increased levels of $H 2$-Ea-specific DNA breaks in testicular germ cells. Mol Cell Biol. 2004; 24:1655-1666. [PubMed: 14749381]

Ramesh MA, Malik SB, Logsdon JM Jr. A phylogenomic inventory of meiotic genes; evidence for sex in Giardia and an early eukaryotic origin of meiosis. Curr Biol. 2005; 15:185-191. [PubMed: 15668177]

Rasmussen SW. Meiosis in Bombyx mori females. Philos Trans R Soc Lond B Biol Sci. 1977; 277:343-350. [PubMed: 16295]

Reddy KC, Villeneuve AM. C. elegans HIM-17 links chromatin modification and competence for initiation of meiotic recombination. Cell. 2004; 118:439-452. [PubMed: 15315757]

Reinholdt LG, Schimenti JC. Meil is epistatic to Dmcl during mouse meiosis. Chromosoma. 2005; 114:127-134. [PubMed: 15928951]

Richard GF, Kerrest A, Lafontaine I, Dujon B. Comparative genomics of hemiascomycete yeasts: genes involved in DNA replication, repair, and recombination. Mol Biol Evol. 2005; 22:10111023. [PubMed: 15647519]

Robine N, et al. Genome-wide redistribution of meiotic double-strand breaks in S. cerevisiae. Mol Cell Biol. 2006

Roca J, Berger JM, Harrison SC, Wang JC. DNA transport by a type II topoisomerase: direct evidence for a two-gate mechanism. Proc Natl Acad Sci USA. 1996; 93:4057-4062. [PubMed: 8633016]

Rockmill B, Roeder GS. RED1: a yeast gene required for the segregation of chromosomes during the reductional division of meiosis. Proc Natl Acad Sci USA. 1988; 85:6057-6061. [PubMed: 3413075]

Rockmill B, Engebrecht JA, Scherthan H, Loidl J, Roeder GS. The yeast MER2 gene is required for chromosome synapsis and the initiation of meiotic recombination. Genetics. 1995; 141:49-59. [PubMed: 8536989]

Romanienko PJ, Camerini-Otero RD. The mouse Spoll gene is required for meiotic chromosome synapsis. Mol Cell. 2000; 6:975-987. [PubMed: 11106738]

Salem L, Walter N, Malone R. Suppressor analysis of the Saccharomyces cerevisiae gene REC104 reveals a genetic interaction with REC102. Genetics. 1999; 151:1261-1272. [PubMed: 10101155]

Sasanuma H, Murakami H, Fukuda T, Shibata T, Nicolas A, Ohta K. Meiotic association between Spo11 regulated by Rec102, Rec104 and Rec114. Nucl Acids Res:epub. 2007 
Sato $\mathrm{H}$, et al. Polymorphic alleles of the human MEII gene are associated with human azoospermia by meiotic arrest. J Hum Genet. 2006; 51:533-540. [PubMed: 16683055]

Scherrer FW Jr. Spingola M. A subset of Mer1p-dependent introns requires Bud13p for splicing activation and nuclear retention. RNA. 2006; 12:1361-1372. [PubMed: 16738408]

Schild D, Byers B. Meiotic effects of DNA-defective cell division cycle mutations of Saccharomyces cerevisiae. Chromosoma. 1978; 70:109-130. [PubMed: 367734]

Sclafani RA. Cdc7p-Dbf4p becomes famous in the cell cycle. J Cell Sci. 2000; 113(Pt 12):2111-2117. [PubMed: 10825284]

Sekelsky JJ, et al. Identification of novel Drosophila meiotic genes recovered in a P-element screen. Genetics. 1999; 152:529-542. [PubMed: 10353897]

Sharif WD, Glick GG, Davidson MK, Wahls WP. Distinct functions of S. pombe Rec12 (Spo11) protein and Rec12-dependent crossover recombination (chiasmata) in meiosis I; and a requirement for Rec12 in meiosis II. Cell Chromosome. 2002; 1:1. [PubMed: 12437782]

Shima H, Suzuki M, Shinohara M. Isolation and characterization of novel xrs2 mutations in Saccharomyces cerevisiae. Genetics. 2005; 170:71-85. [PubMed: 15716496]

Shinohara A, Ogawa H, Ogawa T. Rad51 protein involved in repair and recombination in S. cerevisiae is a RecA-like protein. Cell. 1992; 69:457-470. [PubMed: 1581961]

Smith AV, Roeder GS. The yeast Red1 protein localizes to the cores of meiotic chromosomes. J Cell Biol. 1997; 136:957-967. [PubMed: 9060462]

Smith KN, Nicolas A. Recombination at work for meiosis. Curr Opin Genet Dev. 1998; 8:200-211. [PubMed: 9610411]

Smith KN, Penkner A, Ohta K, Klein F, Nicolas A. B-type cyclins CLB5 and CLB6 control the initiation of recombination and synaptonemal complex formation in yeast meiosis. Curr Biol. 2001; 11:88-97. [PubMed: 11231124]

Spingola M, Ares M. A yeast intronic splicing enhancer and Nam8p are required for Mer1p-activated splicing. Mol Cell. 2000; 6:329-338. [PubMed: 10983980]

Spingola M, Armisen J, Ares M Jr. Mer1p is a modular splicing factor whose function depends on the conserved U2 snRNP protein Snu17p. Nucl Acids Res. 2004; 32:1242-1250. [PubMed: 14973223]

Stacey NJ, et al. Arabidopsis SPO11-2 functions with SPO11-1 in meiotic recombination. Plant J. 2006; 48:206-216. [PubMed: 17018031]

Steiner WW, Schreckhise RW, Smith GR. Meiotic DNA breaks at the S. pombe recombination hot spot M26. Mol Cell. 2002; 9:847-855. [PubMed: 11983175]

Stone MD, et al. Chirality sensing by Escherichia coli topoisomerase IV and the mechanism of type II topoisomerases. Proc Natl Acad Sci USA. 2003; 100:8654-8659. [PubMed: 12857958]

Storlazzi A, Tessé S, Gargano S, James F, Kleckner N, Zickler D. Meiotic double-strand breaks at the interface of chromosome movement, chromosome remodeling and reductional division. Genes Dev. 2003; 17:2675-2687. [PubMed: 14563680]

Stracker TH, Theunissen JW, Morales M, Petrini JH. The Mre11 complex and the metabolism of chromosome breaks: the importance of communicating and holding things together. DNA Repair (Amst). 2004; 3:845-854. [PubMed: 15279769]

Strick TR, Croquette V, Bensimon D. Single-molecule analysis of DNA uncoiling by a type II topoisomerase. Nature. 2000; 404:901-904. [PubMed: 10786800]

Stuart D, Wittenberg C. CLB5 and CLB6 are required for premeiotic DNA replication and activation of the meiotic S/M checkpoint. Genes Dev. 1998; 12:2698-2710. [PubMed: 9732268]

Sugimoto-Shirasu K, Stacey NJ, Corsar J, Roberts K, McCann MC. DNA topoisomerase VI is essential for endoreduplication in Arabidopsis. Curr Biol. 2002; 12:1782-1786. [PubMed: 12401175]

Sugimoto-Shirasu K, Roberts GR, Stacey NJ, McCann MC, Maxwell A, Roberts K. RHL1 is an essential component of the plant DNA topoisomerase VI complex and is required for ploidydependent cell growth. Proc Natl Acad Sci USA. 2005; 102:18736-18741. [PubMed: 16339310] 
Sun H, Treco D, Szostak JW. Extensive 3'-overhanging, single-stranded DNA associated with the meiosis-specific double-strand breaks at the $A R G 4$ recombination initiation site. Cell. 1991; 64:1155-1161. [PubMed: 2004421]

Sym M, Engebrecht JA, Roeder GS. ZIP1 is a synaptonemal complex protein required for meiotic chromosome synapsis. Cell. 1993; 72:365-378. [PubMed: 7916652]

Tessé S, Storlazzi A, Kleckner N, Gargano S, Zickler D. Localization and roles of Ski8p in Sordaria macrospora meiosis and delineation of three mechanistically distinct steps of meiotic homolog juxtaposition. Proc Natl Acad Sci USA. 2003; 100:12865-12870. [PubMed: 14563920]

Theunissen JW, et al. Checkpoint failure and chromosomal instability without lymphomagenesis in Mre 11 $1^{\text {ATLD1/ATLD1 mice. Mol Cell. 2003; 12:1511-1523. [PubMed: 14690604] }}$

Thorne LW, Byers B. Stage-specific effects of X-irradiation on yeast meiosis. Genetics. 1993; 134:29_ 42. [PubMed: 8514137]

Tonami Y, Murakami H, Shirahige K, Nakanishi M. A checkpoint control linking meiotic S phase and recombination initiation in fission yeast. Proc Natl Acad Sci USA. 2005; 102:5797-5801. [PubMed: 15805194]

Tsukamoto Y, Mitsuoka C, Terasawa M, Ogawa H, Ogawa T. Xrs2p regulates Mre11p translocation to the nucleus and plays a role in telomere elongation and meiotic recombination. Mol Biol Cell. 2005; 16:597-608. [PubMed: 15548595]

Usui T, Ohta T, Oshiumi H, Tomizawa J, Ogawa H, Ogawa T. Complex formation and functional versatility of Mre11 of budding yeast in recombination. Cell. 1998; 95:705-716. [PubMed: 9845372]

Usui T, Petrini JH, Morales M. Rad50S alleles of the Mre11 complex: questions answered and questions raised. Exp Cell Res. 2006; 312:2694-2699. [PubMed: 16857186]

Valentin G, Schwob E, Della Seta F. Dual role of the Cdc7-regulatory protein Dbf4 during yeast meiosis. J Biol Chem. 2006; 281:2828-2834. [PubMed: 16319063]

van Heemst D, Heyting C. Sister chromatid cohesion and recombination in meiosis. Chromosoma. 2000; 109:10-26. [PubMed: 10855491]

van Hoof A, Staples RR, Baker RE, Parker R. Function of the Ski4p (Cs14p) and Ski7p proteins in 3'to-5' degradation of mRNA. Mol Cell Biol. 2000; 20:8230-8243. [PubMed: 11027292]

Wahls WP. Meiotic recombination hotspots: shaping the genome and insights into hypervariable minisatellite DNA change. Curr Top Dev Biol. 1998; 37:37-75. [PubMed: 9352183]

Wan L, Zhang C, Shokat KM, Hollingsworth NM. Chemical inactivation of Cdc7 kinase in budding yeast results in a reversible arrest that allows efficient cell synchronization prior to meiotic recombination. Genetics. 2006; 174:1767-1774. [PubMed: 17057233]

Wang JC. Cellular roles of DNA topoisomerases: a molecular perspective. Nat Rev Mol Cell Biol. 2002; 3:430-440. [PubMed: 12042765]

Wang L, Lewis MS, Johnson AW. Domain interactions within the Ski2/3/8 complex and between the Ski complex and Ski7p. RNA. 2005; 11:1291-1302. [PubMed: 16043509]

Ward JO, et al. Toward the genetics of mammalian reproduction: induction and mapping of gametogenesis mutants in mice. Biol Reprod. 2003; 69:1615-1625. [PubMed: 12855593]

Watanabe Y, Nurse P. Cohesin Rec8 is required for reductional chromosome segregation at meiosis. Nature. 1999; 400:461-464. [PubMed: 10440376]

Webber HA, Howard L, Bickel SE. The cohesion protein ORD is required for homologue bias during meiotic recombination. J Cell Biol. 2004; 164:819-829. [PubMed: 15007062]

Wells JL, Pryce DW, Estreicher A, Loidl J, McFarlane RJ. Linear element-independent meiotic recombination in Schizosaccharomyces pombe. Genetics. 2006

Wiltzius JJ, Hohl M, Fleming JC, Petrini JH. The Rad50 hook domain is a critical determinant of Mre11 complex functions. Nat Struct Mol Biol. 2005; 12:403-407. [PubMed: 15852023]

Wu T-C, Lichten M. Meiosis-induced double-strand break sites determined by yeast chromatin structure. Science. 1994; 263:515-518. [PubMed: 8290959]

Wu T-C, Lichten M. Factors that affect the location and frequency of meiosis-induced double-strand breaks in Saccharomyces cerevisiae. Genetics. 1995; 140:55-66. [PubMed: 7635308] 
Xiao Y, Weaver DT. Conditional gene targeted deletion by Cre recombinase demonstrates the requirement for the double-strand break repair Mre11 protein in murine embryonic stem cells. Nucl Acids Res. 1997; 25:2985-2991. [PubMed: 9224597]

Xu F, Petes TD. Fine-structure mapping of meiosis-specific double-strand DNA breaks at a recombination hotspot associated with an insertion of telomeric sequences upstream of the HIS4 locus in yeast. Genetics. 1996; 143:1115-1125. [PubMed: 8807286]

Xu L, Kleckner N. Sequence non-specific double-strand breaks and interhomolog interactions prior to double-strand break formation at a meiotic recombination hot spot in yeast. EMBO J. 1995; 14:5115-5128. [PubMed: 7588640]

Xu L, Weiner BM, Kleckner N. Meiotic cells monitor the status of the interhomolog recombination complex. Genes Dev. 1997; 11:106-118. [PubMed: 9000054]

Yamamoto, M.; Imai, Y.; Watanabe, Y. Mating and sporulation in Schizosaccharomyces pombe. In: Pringle, JR.; Broach, JR.; Jones, EW., editors. The Molecular and Cellular Biology of the Yeast Saccharomyces: Life Cycle and Cell Biology. Cold Spring Harbor, NY: Cold Spring Harbor Laboratory Press; 1997. p. 1035-1106.

Yin Y, et al. A crucial role for the putative Arabidopsis topoisomerase VI in plant growth and development. Proc Natl Acad Sci USA. 2002; 99:10191-10196. [PubMed: 12119417]

Young JA, Schreckhise RW, Steiner WW, Smith GR. Meiotic recombination remote from prominent DNA break sites in S. pombe. Mol Cell. 2002; 9:253-263. [PubMed: 11864600]

Young JA, Hyppa RW, Smith GR. Conserved and nonconserved proteins for meiotic DNA breakage and repair in yeasts. Genetics. 2004; 167:593-605. [PubMed: 15238514]

Zenvirth D, Arbel T, Sherman A, Goldway M, Klein S, Simchen G. Multiple sites for double-strand breaks in whole meiotic chromosomes of Saccharomyces cerevisiae. EMBO J. 1992; 11:34413447. [PubMed: 1324174]

Zenvirth D, et al. Mammalian meiosis involves DNA double-strand breaks with 3' overhangs. Chromosoma. 2003; 111:369-376. [PubMed: 12644952]

Zhu J, Petersen S, Tessarollo L, Nussenzweig A. Targeted disruption of the Nijmegen breakage syndrome gene NBS1 leads to early embryonic lethality in mice. Curr Biol. 2001; 11:105-109. [PubMed: 11231126] 


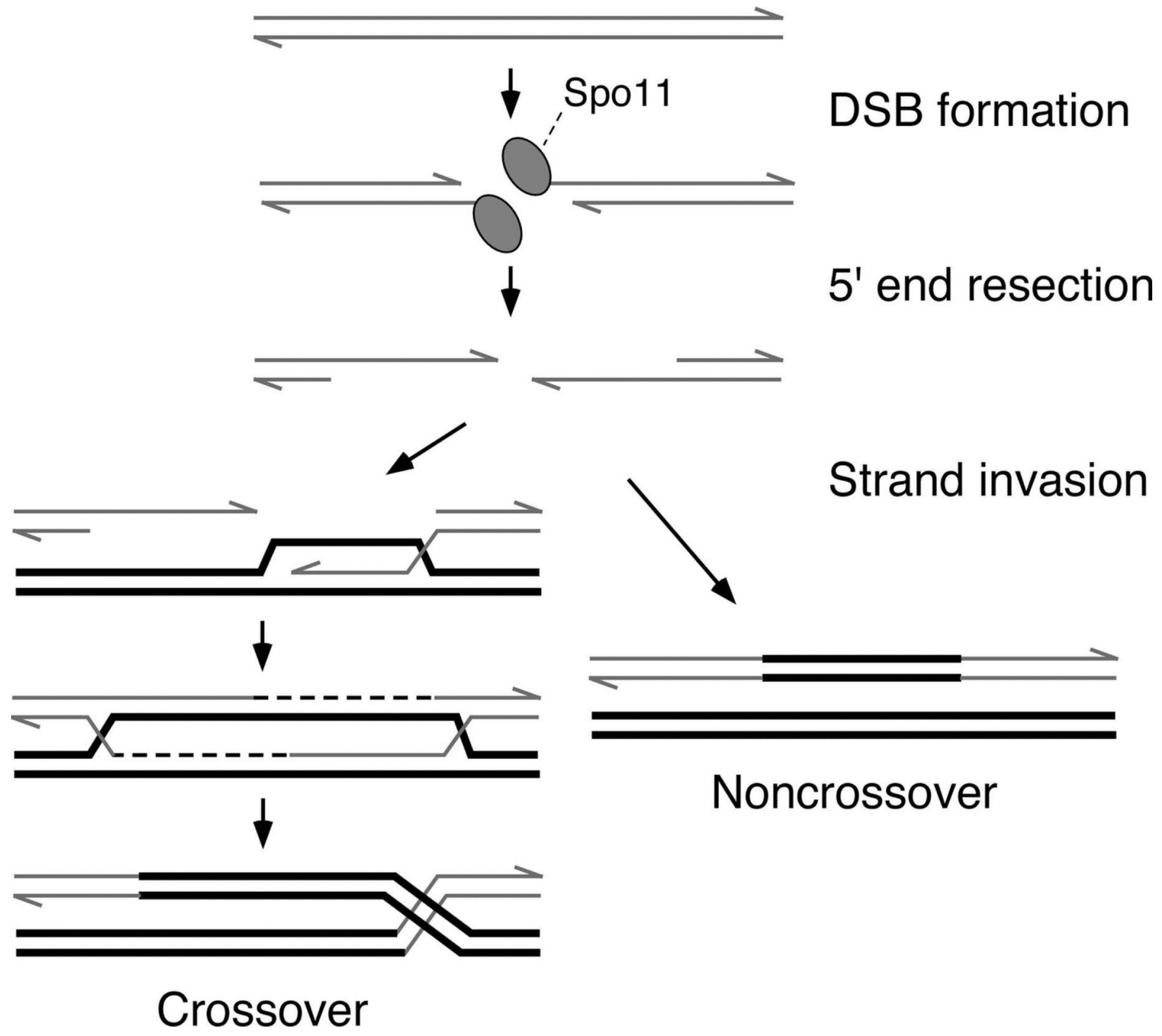

Figure 1. Overview of meiotic recombination pathway in $S$. cerevisiae

Schematic figures of the DNA at different steps (precursor, intermediates, and products) are shown. Proteins are omitted except for Spo11, which becomes covalently attached to the DNA as part of the DNA cleavage reaction. Only one of the two sister chromatids from each homolog. See text for details. 


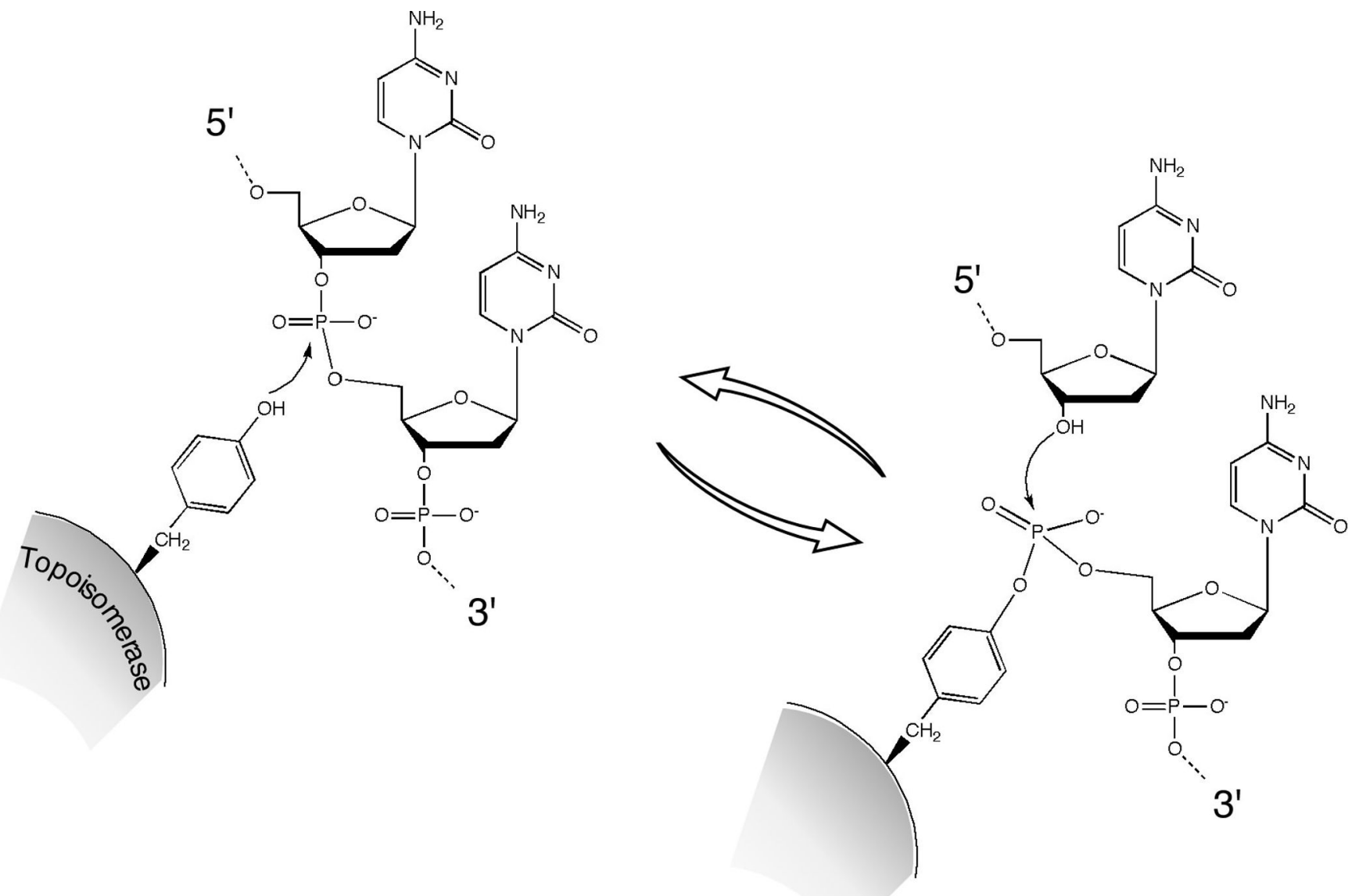

Figure 2. Chemistry of the DNA cleavage and religation reactions catalyzed by topoisomerases A tyrosine side chain on the topoisomerase protein carries out a nucleophilic attack on the DNA phosphodiester backbone. This transesterase reaction severs the DNA backbone and covalently links the protein to the DNA end via a tyrosyl phosphodiester linkage. The protein-DNA linkage is reversed and the DNA is resealed by attack of the deoxyribose hydroxyl. In this example, the tyrosyl phosphodiester links the protein to the $5^{\prime}$ end of the cleaved strand, as is seen in some type I and all type II topoisomerases. For a type II enzyme, two topoisomerase monomers work in concert to cleave the two strands of the duplex. 


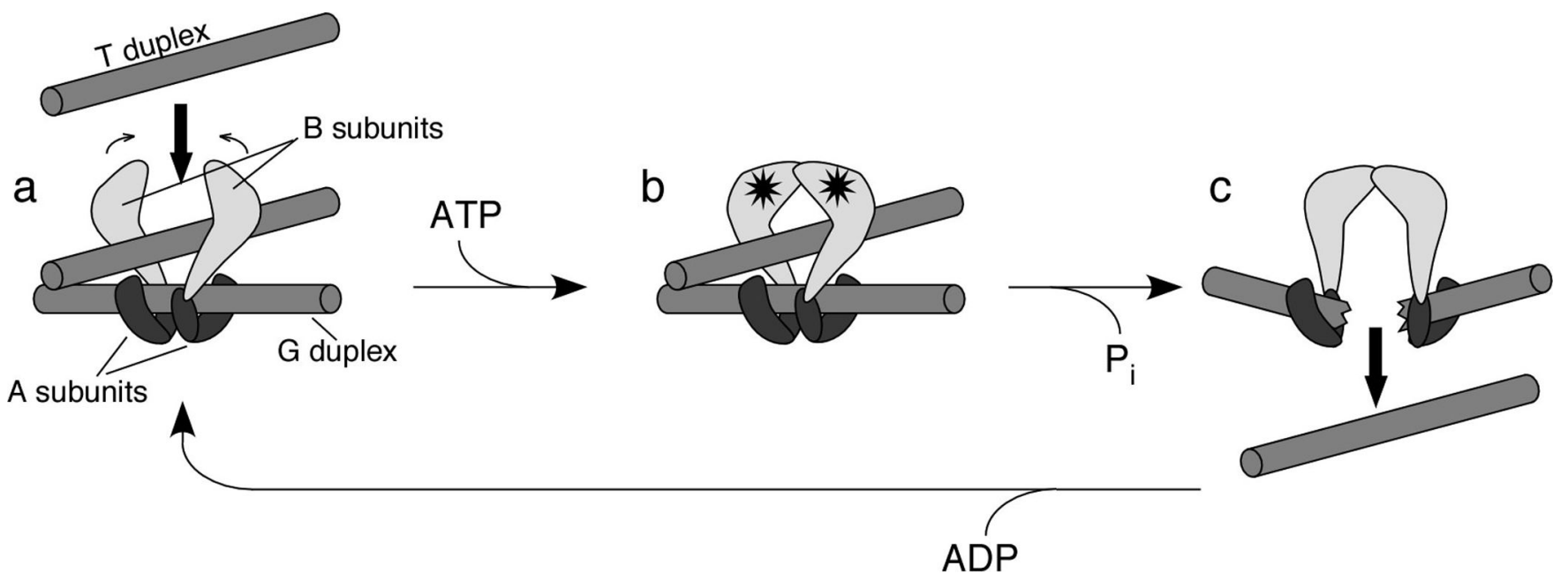

Figure 3. Structural model for the catalytic cycle of topoisomerase VI

A two-gate model for TopoVI action has been proposed based on enzymatic and structural studies (Corbett and Berger 2004). Two B subunits are proposed to bind to a dimer of A subunits. The subunit-B binding interface on A is thought to reside on the CAP domain, which also contains the catalytic tyrosine residue. The dimer of A subunits binds to the DNA duplex that will be cleaved (the $G$, or gate, duplex). A second DNA duplex (the T, or transfer, duplex) enters the enzyme through a gate between the ATPase domains of the B subunits (panel a). ATP binding (stars) induces dimerization of the B subunits, trapping the T duplex (panel b). A conformational change accompanying ATP hydrolysis and DNA cleavage opens a gate in the $\mathrm{G}$ duplex, through which the $\mathrm{T}$ duplex is expelled (panel c). Release of ADP and resealing of the G duplex recycle the enzyme to its starting state. The figure is adapted, with permission, from the Annual Review of Biophysics and Biomolecular Structure, Vol. 33 (c)2004 by Annual Reviews (www.annualreviews.org). 

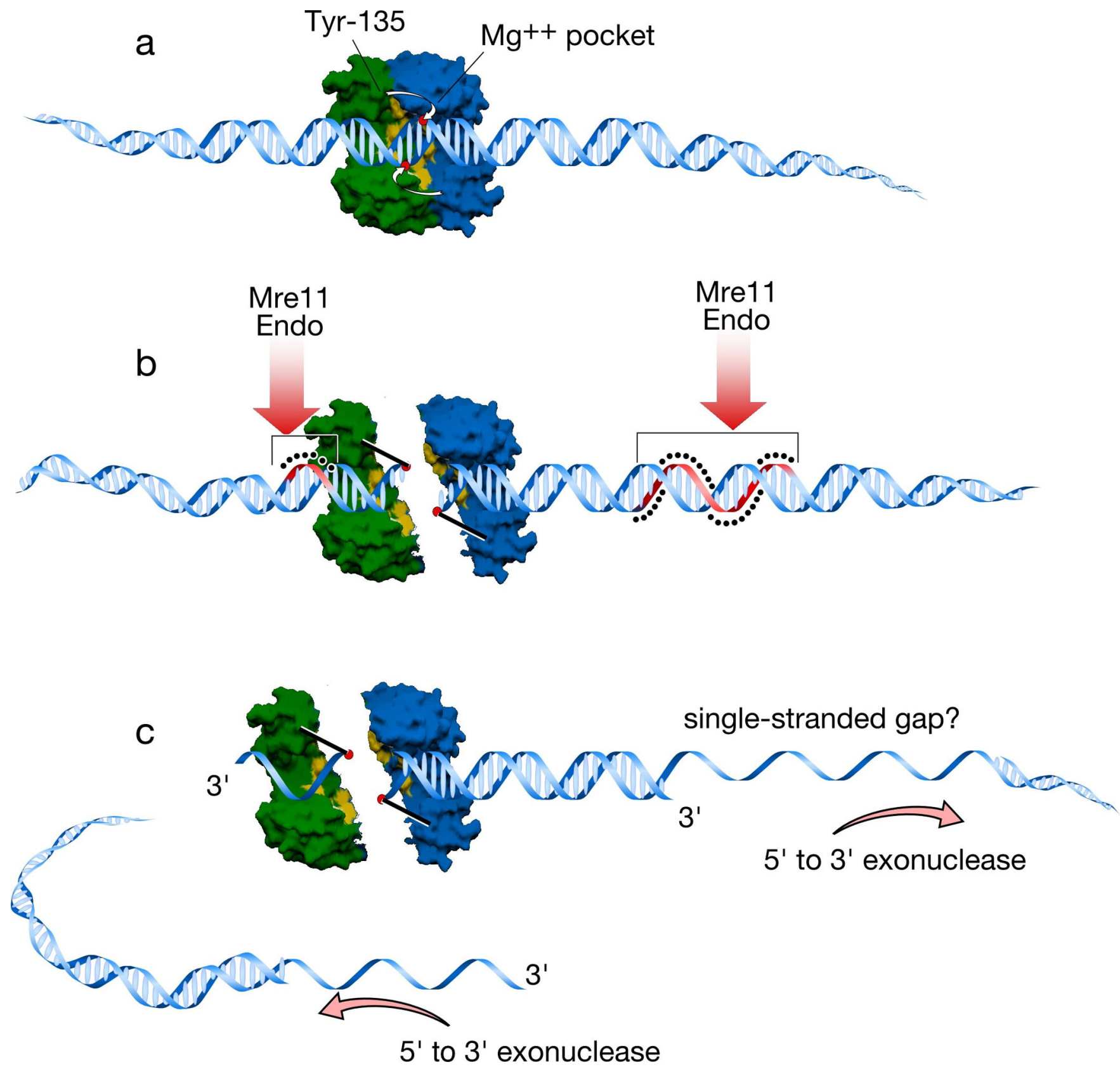

Figure 4. Structural model for Spo11-induced DSB formation

a. A Spo11 dimer is modeled using a surface rendering of the structure of Methanococcus jannaschi TopoVIA, with one monomer in green and the other in blue (Nichols et al. 1999). Approximate positions of the catalytic tyrosine of one monomer and the metal-binding pocket of the other monomer are indicated. B-form DNA (drawn approximately to scale) is docked onto the dimer. The metal binding pockets of the two monomers are appropriately spaced to place them in proximity to the scissile phosphates which would give the twonucleotide 5' overhang known to be generated by Spo11 and TopoVI. The tyrosines in the TopoVIA structure are far from these phosphates, however, so it is assumed that a conformational change in the protein moves the tyrosines into position to cleave (Nichols et al. 1999) (small white arrows). 
b. Cleavage of the DNA backbone leaves Spo11 covalently attached to the DSB ends. For clarity, the Spo11 dimer interface has been interrupted to show how the two monomers are attached. Analogous separation of the DNA ends is what opens a gate to allow strand passage for TopoVI (Corbett and Berger 2004); whether the Spo11 dimer interface might be disrupted in this manner is not known (see Section 5). After DNA cleavage, Spo11 is released from DSB ends by endonucleolytic single-strand cleavage on either side of the break, most likely mediated by Mre11 endonuclease activity. The strands where nicking occurs are colored red and highlighted with the black dots. Asymmetric nick spacing is shown, but the disposition of nicks around individual DSBs is not yet known.

c. The DSB ends are further processed by $5^{\prime} \rightarrow 3^{\prime}$ single-strand resection. The shorter Spo11bound oligonucleotides may be small enough to be readily dissociated, but the longer oligonucleotides would need to be actively unwound. This feature may result in capping of one of the DSB ends, which may in turn influence the behavior of this end during subsequent recombination reactions (Neale et al. 2005). 


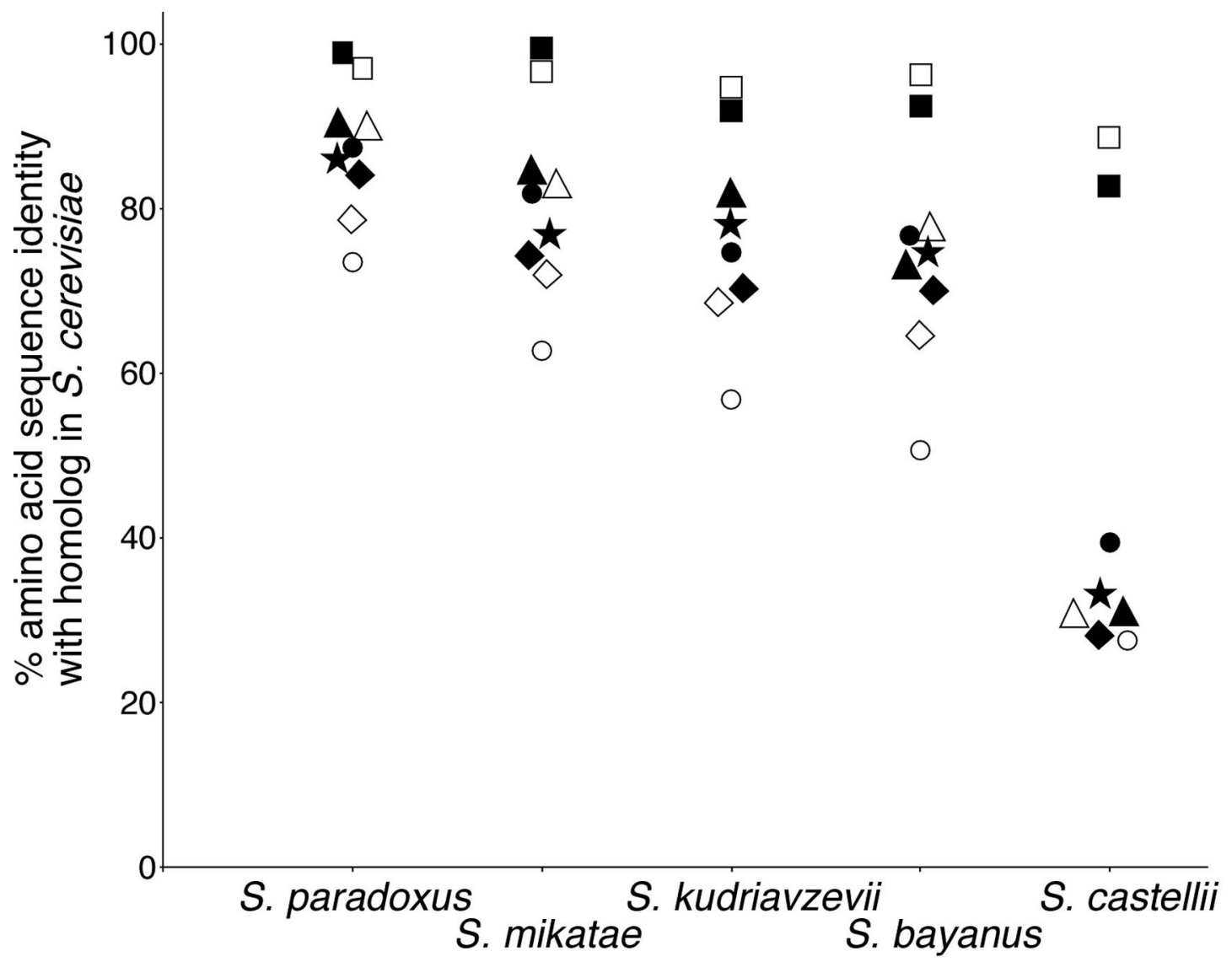

Figure 5. Rapid divergence of DSB proteins

The sequence conservation (\% amino acid identity) between $S$. cerevisiae and each of several other Saccharomyces species is shown for the indicated proteins. DSB proteins diverge rapidly, especially when compared with two examples of mitotically expressed proteins, Rad51 and Arg4. Remarkably, Rec104 and Rec114 are less than 80\% conserved even in S. paradoxus, a very close sibling of S. cerevisiae. A Rec104 homolog was not detected in the $S$. castellii genome sequence. Note that this analysis is not meant to imply that DSB proteins are uniquely prone to rapid divergence, although it has been demonstrated that meiotic recombination proteins in general tend to be among the cell's most divergent (Richard et al. 2005). Rather, the point is that they do diverge rapidly and may thus be difficult to identify by routine sequence homology searches in evolutionarily more distant organisms. 

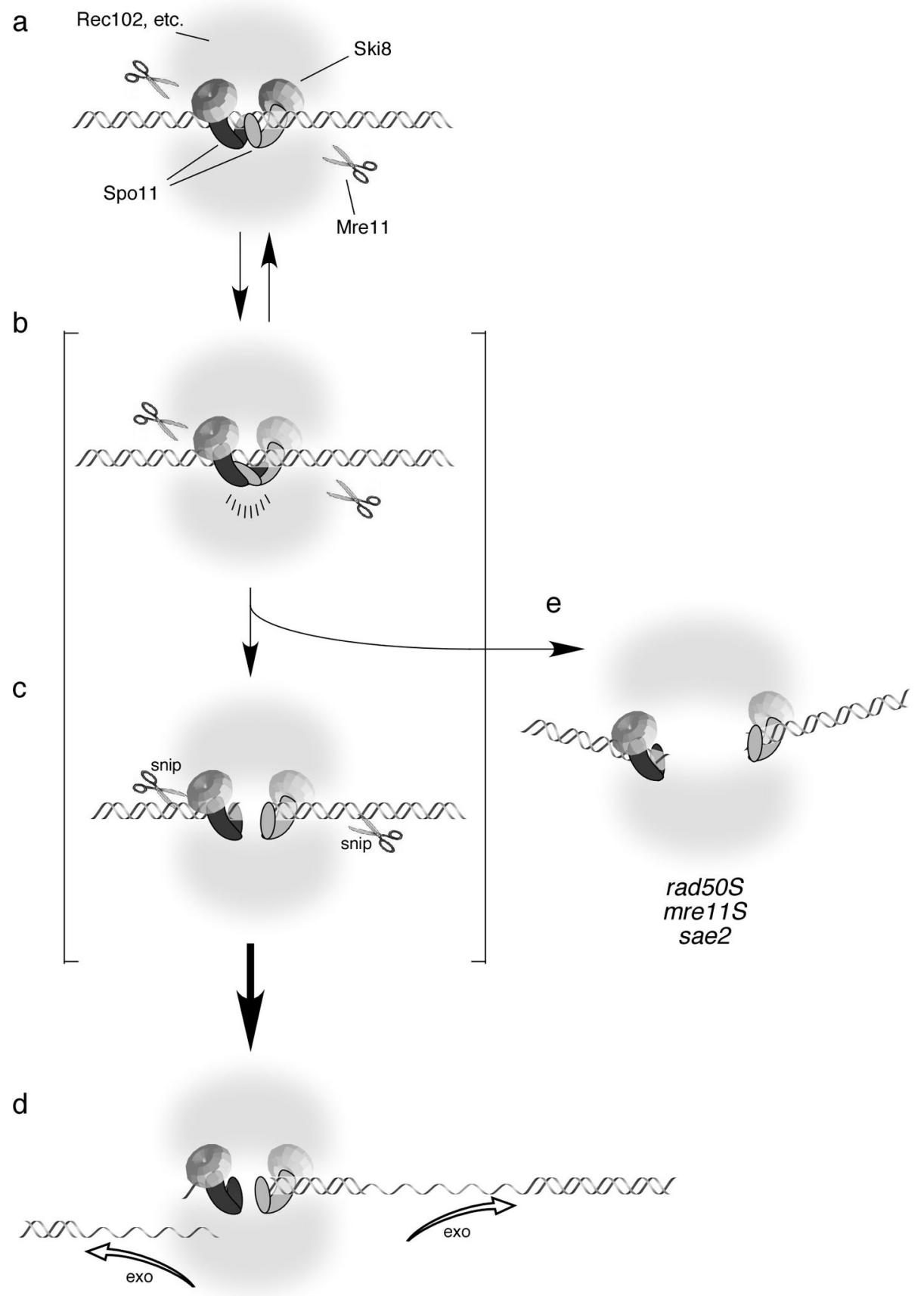

Figure 6. Model for the mechanism of DSB formation

Spo11 is represented as for TopoVIA in Figure 3. The WD repeat protein Ski8 is shown as a donut bound to Spo11, Mre11 endonuclease as a pair of scissors, and other DSB proteins ("Rec102, etc.") as clouds encompassing the Spo11 complex on DNA. Key features of this model are that Spo11 binding to DNA and activation to cleave are separate steps (Prieler et al. 2005); DNA cleavage by Spo11 and the onset of DSB processing by Mre11 (with or without other nucleases) are concerted reactions; and the irreversible Spo11-bound DSBs in rad50S and other mutants are off-pathway (Prieler et al. 2005).

a. Assembly of a pre-DSB complex on DNA, consisting of Spo11, Ski8, and at least a subset of the other DSB proteins. 
b, c. Activation of Spo11 to cleave DNA. In panel b, conformational change within the complex (perhaps within Spo11 itself) renders Spo11 competent to cleave DNA, but it has not yet done so. This complex may be reversed without forming a DSB. In panel c, activated Spo11 complexes are competent to be driven forward: Spo11 forms a DSB and, in a concerted reaction, Mre11 nicks the DNA to initiate processing of the DSB. This sub-step is irreversible and commits this site to undergoing homologous recombination.

d. Exonucleolytic processing. Further degradation of the $5^{\prime}$ terminal strands follows rapidly and in a concerted manner upon DSB formation and Mre11 nucleolytic activity.

e. Irreversible DSB formation in rad50S, mre11S, and sae2 mutants. Activation of Spo11 in the absence of Mre11 nuclease activity stabilizes the complex (Prieler et al. 2005), but a frank DSB cannot form because concerted processing by Mre11 cannot occur. This complex eventually decays to give an irreversible DSB that is related to normal meiotic DSBs but that is off the normal pathway. 